\title{
Flavonoid engineering of flax potentiate its biotechnological application
}

\author{
Magdalena Żuk ${ }^{1,5^{*}}$, Anna Kulma1', Lucyna Dymińska², Katarzyna Szołtysek², Anna Prescha ${ }^{3}$ Jerzy Hanuza ${ }^{2,4}$, \\ Jan Szopa ${ }^{1,5}$
}

\begin{abstract}
Background: Flavonoids are a group of secondary plant metabolites important for plant growth and development. They show also a protective effect against colon and breast cancer, diabetes, hypercholesterolemic atherosclerosis, lupus nephritis, and immune and inflammatory reactions. Thus, overproduction of these compounds in flax by genetic engineering method might potentiate biotechnological application of these plant products.

Results: Flax plants of third generation overexpressing key genes of flavonoid pathway cultivated in field were used as plant material throughout this study. The biochemical properties of seed, oil and seedcake extracts and fibre from natural and transgenic flax plants were compared. The data obtained suggests that the introduced genes were stably inherited and expressed through plant generations.

Overproduction of flavonoid compounds resulted in increase of fatty acids accumulation in oil from transgenic seeds due to protection from oxidation offered during synthesis and seed maturation. The biochemical analysis of seedcake extracts from seeds of transgenic flax revealed significant increase in flavonoids (kaempferol), phenolic acids (coumaric, ferulic, synapic acids) and lignan content. Fibres, another product of flax plant showed increase in the level of catechine and acetylvanillone and decrease in phenolic acids upon flax modification.

Biochemical analysis results were confirmed using IR spectroscopy. The integral intensities of IR bands have been used for identification of the component of phenylpropanoid pathway in oil, seedcake extract and fibre from control and transgenic flax. It was shown that levels of flavonoids, phenolic acids and lignans in oil and seedcake extract was higher in transgenic flax products compared to control. An FT-IR study of fibres confirmed the biochemical data and revealed that the arrangement of the cellulose polymer in the transgenic fibres differs from the control; in particular a significant decrease in the number of hydrogen bonds was detected.
\end{abstract}

Conclusions: All analysed products from generated transgenic plants were enriched with antioxidant compounds derived from phenylopropanoid pathway Thus the products provide valuable source of flavonoids, phenolic acids and lignan for biomedical application. The compounds composition and quantity from transgenic plants was confirmed by IR spectroscopy. Thus the infrared spectroscopy appeared to be suitable method for characterization of flax products.

\section{Background}

Flax (Linum usitatissimum) plant has a long history of traditional use both as a source of oil and fibre and is grown for commercial use in over 30 countries of the world. In Poland, flax is the most important industrial oil and fibre crop.

Flax seeds have long been used in human and animal diet and in industry as a source of oil and as the basal

\footnotetext{
* Correspondence: mzuk@ibmb.uni.wroc.pl

${ }^{1}$ Faculty of Biotechnology, University of Wrocław, Poland

Full list of author information is available at the end of the article
}

component or additive of various paints or polymers. Recently there has been a growing interest in the probiotic properties of flax and in its beneficial effects on coronary heart disease, some kinds of cancer and neurological and hormonal disorders [1-3]. The beneficial effects are mostly due to flax lipids. Flax oil is the richest plant source of linoleic and linolenic polyunsaturated fatty acids (PUFA), which are essential for humans since they cannot be synthesized in the organism and must be ingested with food.
C Biomed Central

(c) 2011 Żuk et al; licensee BioMed Central Ltd. This is an Open Access article distributed under the terms of the Creative Commons Attribution License (http://creativecommons.org/licenses/by/2.0), which permits unrestricted use, distribution, and reproduction in any medium, provided the original work is properly cited. 
Unfortunately, essential fatty acids are highly susceptible to oxidation and flax oil therefore has a very short shelf life. Only certain cultivars (e.g. Linola) with appropriate lipid composition are suitable for commercial preparation of edible oil $[4,5]$. In flax grains, lipids are suitably protected against oxidation by various mechanisms and the antioxidative effect of phenylpropanoids which are present in seedcake is among them. However, even after cold extraction most of these mechanisms are no longer operative and phenylpropanoids as hydrophilic compounds are not effectively extracted with oil, remaining associated with seedcakes.

Therefore seedcake, which is defatted seed, might appear as a good source of easily extracted compounds of phenylpropanoids pathway with antioxidant activity. The antioxidant compounds extracted from seedcake might have potential application in medicine. It was already suggested the beneficial role of kaemferol and quercetin as well as lignans for human in preventing against different types of cancer, cardiovascular diseases and diabetes. Very recently the extract from seedcakes was successfully used as a component of new bandage for healing of human chronic ulceration [6,7].

To avoid a fast appearance of rancidity, flax oil is often cold-pressed, supplemented with vitamin A and E or stored in dark glass jars. Since none of these protection methods are fully satisfactory, further improvements are looked for. Genetic engineering approach could involve the overproduction of various natural antioxidants within flax grains. In addition to preventing fat rancidity, antioxidants such as flavonoids might also have beneficial effect on human health.

Plant phenylpropanoids are very broad group of biochemical compounds, which form secondary metabolites in the enzymatic biosynthesis. They include flavonoids, phenolic acids, phenols, lignans and tannins [8-10]. Flavonoids are involved in many biochemical processes of plant growth and development. They act as antioxidants, chelators of divalent cations [11] photoreceptors and visual attractors [12] They protect plants against pathogenic micro-organisms [13], herbivores, UV radiation [14] and oxidative and heat stresses. Their antioxidant activity influences the food quality due to their inhibitory action on enzymatic and non-enzymatic peroxidation [15]. Flavonoids also exhibit anti-allergic, antiviral, anti-inflammatory and vasodilatory activities $[12,16]$.

Thus the aim of our previous study was to increase antioxidant potential (via overexpression of regulatory genes of phenylpropanoid pathway) of flax for greater accumulation of PUFA and its higher stability against oxidation. Indeed simultaneous overexpression of chalcone synthase (CHS), chalcone isomerase ( $\mathrm{CHI}$ ) and dihydroflavonol reductase (DFR) resulted in significant accumulation of flavonoids in seeds extract and thus the increase stability of unsaturated fatty acids against oxidation was detected $[17,18]$.

The aim of this work was to analyze separately oil and seedcake extracts as well as fibers for the presence and content of biologically active compounds by liquid chromatography and IR spectroscopy in order to determine their possible applications. Simultaneous use of those two techniques allow for a obtaining of much more complete data. When liquid chromatography (UPLC) is satisfactory for identification and measurements of quantity of compounds, however it does not always provide data on the structure of newly synthesized phenylpropanoids, their potential modification and their presence in fiber and oil. The last was of special interest for the reason that hydrophilic flavonoids are present in oil in trace amount and therefore their content and structural analysis in respect to their antioxidative role might be biotechnologically useful. Therefore FT-IR spectroscopy was used in the characterization of seed oil, seedcake extracts and fibres for their chemical composition and molecular changes.

\section{Methods \\ Transgenic flax generation and selection Plant material}

Flax seeds (cv. Linola) were obtained from The Flax and Hemp Collection of the Institute of Natural Fibres, Poland. Initially the transgenic and control plants were grown in tissue culture and were cultivated in a greenhouse under a $16 \mathrm{~h}$ light $\left(21^{\circ} \mathrm{C}\right), 8 \mathrm{~h}$ darkness $\left(16^{\circ} \mathrm{C}\right)$ regime. Next the plants were grown in soil in individual pots and were watered daily. Finally the seeds were used for plant propagation in a field. In this work third generation of transgenic seeds were grown in a field, and seeds were harvested 4 months after the transfer of the seeds to the soil.

\section{Transgenic plant construction and selection}

Two-week old cotyledon and hypocotyl explants were transformed. For transformation, we used the binary vector containing three cDNAs from Petunia hybrida, encoding chalcone synthase (CHS, EMBL/GenBank database acc. no. X04080), chalcone isomerase (CHI, EMBL/GenBank database acc. no. X14589) and dihydroflavonol reductase (DFR, EMBL/GenBank database acc. no. $\mathrm{X} 15537)$ in the sense orientation under the control of the $35 \mathrm{~S}$ promoter and OCS terminator [19].

The vector was introduced into Agrobacterium tumefaciens strain C58C1: pGV2260. A. tumefaciens-inoculated explants were subsequently transferred to a callus induction and shoot regeneration medium [20].

The transgenic plants were preselected via PCR using primers specific for the kanamycin resistance gene (npt II), and then selected by means of northern blot analysis. PCR was carried out using specific primers for the neomycine phosphotransferase gene (forward, 
CCGACCTGTCCGGTGCCC; reverse, CGCCACACCCAGCCGGCC) on genomic DNA isolated from 3-week old tissue-cultured plants as a template.

Total RNA was prepared from frozen young leaves using the guanidinium hydrochloride method [21]. Total RNA was separated on an agarose gel (1.5\% (w/v) agarose, $15 \%(\mathrm{v} / \mathrm{v})$ formaldehyde) and blotted onto a Hybond $\mathrm{N}+$ (Amersham) filter. The membrane was hybridized overnight at $42^{\circ} \mathrm{C}$ with radiolabeled cDNAs (CHS, CHI, and DFR) as probes and then washed three times with SSPE buffer containing $0.1 \%$ SDS for $30 \mathrm{~min}$ at $42^{\circ} \mathrm{C}$.

The details on plant transformation, selection and transgenic plant analysis was described previously [17].

\section{Oil and seedcake preparation}

$25 \mathrm{~kg}$ of flax seeds was used for pressing of oil on industrial worm gear oil press (Oil PressDD85G - IBG Monoforts Oekotec GmbH\& Co). Flax seeds were grounded and transferred to press machine for cold pressing of oil. The mean yield of procedure is $25 \%$ oil and $75 \%$ seedcakes. Oil and seedcakes were collected and used for further experiments.

\section{Biochemical analysis of oil}

\section{Determination of fatty acids content in oil}

Methyl esters of fatty acids (FAMEs) were extracted from oil using $0.5 \mathrm{M} \mathrm{KOH}$ in methanol. After that sample was neutralized using $1.25 \mathrm{M} \mathrm{HCl}$ in methanol. Then methyl esters of fatty acids were extracted into hexane. The hexane phase was collected; the lipids were concentrated in $\mathrm{N}_{2}$ stream and stored at $-20^{\circ} \mathrm{C}$. The methyl esters were quantified by gas chromatography (Agilent Technology 6890N with FID detector), using pentadecanoic acid as an internal standard [22].

\section{Determination of phenolic compounds in oil}

Total phenolic compounds was measured using FolinCiocalteu method [23] in methanol extracts $(90 \% \mathrm{v} / \mathrm{v})$ from oil. The phenolic compounds content was calculated as equivalents of caffeic acid.

\section{Determination of tocopherols, plastochromanol-8 and $\beta$-carotene}

Tocopherols and plastochromanol- 8 and $\beta$-carotene contents were determined by high-performance liquid chromatography (HPLC- Waters Milford 600 with fluorimetric detector, excitation $290 \mathrm{~nm}$, emission $330 \mathrm{~nm}$ ) with $\beta$-tocopherol as internal standard. The samples were first analyzed without internal standard to confirm the absence of $\beta$-tocopherol. For analysis of $\beta$ carotene the UV-VIS detector $(450 \mathrm{~nm})$ was used [24].

\section{Antioxidant potential of oil}

\section{Peroxide value measurement in oil}

The peroxide value is determined by measuring the amount of iodine which is formed by the reaction of peroxides (formed in oil) with iodine ion. Peroxide value was measured as content of $\mathrm{mol} / \mathrm{dm}^{3}$ sodium thiosulfate $\left(\mathrm{Na}_{2} \mathrm{~S}_{2} \mathrm{O}_{3}\right)$.

\section{TBARS measurements in oil}

The level of TBARS (thiobarbituric acid-reactive substances) was measured according to the published protocol [18]. Oil samples $(4 \mu \mathrm{l})$ were oxidized at $140^{\circ} \mathrm{C}$ for $40 \mathrm{~min}$ in tightly closed glass test tubes, using laboratory oven. After the initial baking time, $2 \mathrm{ml}$ of reagent (15\% TCA and $0.37 \%$ TBA in $0.25 \mathrm{M} \mathrm{HCL}$ ) was added to each sample, and the mixture was thoroughly blended. Then the test tubes were heated at $100^{\circ} \mathrm{C}$ for $15 \mathrm{~min}$ and cooled under running tap water. After a 10-min centrifuge, the absorbance at $535 \mathrm{~nm}$ was measured.

Preparation and biochemical analysis of seedcake extracts HPLC analysis of flavonoid glycoside content

The materials used in this study were crushed using a laboratory mill. A $1 \mathrm{~g}$ sample of flax seedcakes was extracted with $7 \mathrm{ml} \mathrm{35 \%}$ aqueous methanol containing $1 \mathrm{~g} / \mathrm{L} \mathrm{L}$-ascorbic acid as an antioxidant, for $18 \mathrm{~h}$ at $20^{\circ} \mathrm{C}$ in glass screw-capped vials, and then sonicated for $15 \mathrm{~min}$. Next, the samples were centrifuged $(5 \mathrm{~min}$, $19,000 \mathrm{~g})$ and the clear supernatant was injected onto a HPLC column. The analysis of flavones and flavonols derivatives were carried out on a Merck-Hitachi L7455 liquid chromatograph with a diode array detector (DAD) and quaternary pump L-7100 equipped with D7000 HSM Multisolvent Delivery System (Merck-Hitachi, Tokyo, Japan) and an L-7200 auto sampler. Separation was performed on a Synergi Fusion RP-80A $150 \times$ $4.6 \mathrm{~mm}(4 \mu \mathrm{m})$ Phenomenex (Torrance, CA, USA) column. The oven temperature was set to $20^{\circ} \mathrm{C}$. The mobile phase was composed of solvent A (2.5\% acetic acid) and solvent $B$ (acetonitrile). The program began with a linear gradient from $0 \%$ B to $25 \%$ B at $36 \mathrm{~min}$, followed by washing and reconditioning of the column. The flow rate was $1.0 \mathrm{~mL} / \mathrm{min}$, and the runs were monitored at the following wavelengths: flavones at $340 \mathrm{~nm}$ and flavonols derivatives at $360 \mathrm{~nm}$.

\section{Determination of the total anthocyanin glycoside content via the $\mathrm{pH}$-differential method}

$15 \mathrm{mg}$ of seedcakes was extracted with $1 \mathrm{~mL}$ of metha$\mathrm{nol} / \mathrm{HCl}(95: 5, \mathrm{v} / \mathrm{v})$ in an ultrasonic bath for $30 \mathrm{~min}$. The extract was centrifuged at $14,000 \mathrm{~g}$ for $10 \mathrm{~min}$. Two dilutions of the sample were performed: first, $100 \mu \mathrm{L}$ of the supernatant was mixed with $900 \mu \mathrm{L}$ of $0.025 \mathrm{M}$ potassium chloride buffer, $\mathrm{pH} \mathrm{1.0,} \mathrm{and} \mathrm{then,}$ $100 \mu \mathrm{L}$ of supernatant was mixed with $900 \mu \mathrm{L}$ of $0.4 \mathrm{M}$ sodium acetate buffer, $\mathrm{pH} 4.5$. The solution was allowed to stand at RT for $15 \mathrm{~min}$, and then the absorbance at $510 \mathrm{~nm}$ and $700 \mathrm{~nm}$ was measured, which allowed for haze correction. The results were reported as cyanidin3-O-glucoside equivalents 


\section{Preparation of alkali hydrolyzed seedcake extract}

Flax seedcakes $(100 \mathrm{~g})$ were extracted three times with $400 \mathrm{ml}$ of $80 \%$ methanol $(\mathrm{v} / \mathrm{v})$ for $15 \mathrm{~min}$ at $80^{\circ} \mathrm{C}$. The extract was centrifuged, pellet discarded and methanol from supernatant fraction evaporated at $40^{\circ} \mathrm{C}$. The aqueous fraction of extract was subjected to alkaline hydrolysis in final concentration $0.3 \mathrm{M}$ sodium hydroxide for 2 days at room temperature followed by neutralization using $2 \mathrm{M}$ hydrochloric acid. Neutralized extract was centrifuged and supernatant was sterilized by filtration through Acrodisc (Gelman Sciences, Ann Arbor, MI) $0.22 \mu \mathrm{m}$ filter or by autoclaving at $120^{\circ} \mathrm{C}$ for $20 \mathrm{~min}$ [25].

Secoisolariciresinol diglucoside (SDG) content measurement The seedcake extract after alkali hydrolysis was analyzed on Waters Acquity UPLC System with a 2996 PDA detector, using Acquity UPLC column BEH C18, $2.1 \times$ $100 \mathrm{~mm}, 1.7 \mu \mathrm{m}$. The mobile phase of $\mathrm{A}=$ acetonitrile/ $\mathrm{B}=20 \mathrm{mM}$ ammonium formate $\mathrm{pH} 3$ in a gradient flow: $1 \mathrm{~min} .10 \% / 90 \% \mathrm{~A} / \mathrm{B}, 2-10 \mathrm{~min}$. gradient to $30 \% /$ $70 \% \mathrm{~A} / \mathrm{B}, 12 \mathrm{~min}$ gradient from $30 \%$ to $100 \% \mathrm{~A}$, and 13 min gradient from $100 \% \mathrm{~A}$ to $10 \% / 90 \% \mathrm{~A} / \mathrm{B}$ with a $0.4 \mathrm{~mL} / \mathrm{min}$ flow rate. The compound content was measured at $320 \mathrm{~nm}$ [25].

\section{Phenolic acid content measurement}

The seedcake extract after alkali hydrolysis was analyzed on Waters Acquity UPLC System with a 2996 PDA detector, using Acquity UPLC column BEH C18, $2.1 \times$ $100 \mathrm{~mm}, 1.7 \mu \mathrm{m}$. The mobile phase of $\mathrm{A}=$ acetonitrile/ $\mathrm{B}=20 \mathrm{mM}$ ammonium formate $\mathrm{pH} 3$ in a gradient flow: 1 min. 10\%/90\% A/B, 2-6 min. gradient to $40 \% /$ $60 \%$ A/B, 7 min gradient from $40 \%$ to $100 \%$ A, and 8 min gradient from $100 \% \mathrm{~A}$ to $10 \% / 90 \% \mathrm{~A} / \mathrm{B}$ with a $0.4 \mathrm{~mL} / \mathrm{min}$ flow rate. The compound was measured at $280 \mathrm{~nm}$ [25].

\section{Antioxidant capacity of seedcake extract}

The chemiluminescence method was used to determine the antioxidant activity of the extracts. A methanol (100\%) extract of flax was diluted in the range of 1000-15.000 times with water, and directly analyzed according to the published method of Lukaszewicz et al. [26]. This experiment was performed in a final volume of $250 \mu \mathrm{L}$ on white microplates in a solution containing $0.1 \mathrm{M}$ Tris- $\mathrm{HCl}$ buffer, $\mathrm{pH} 9.0$, and $4 \mathrm{mM}$ 2.2-azobis (2amidinopropane) dihydrochloride (AAPH), freshly prepared. The luminol solution $(100 \mathrm{mM})$ and diluted extract were automatically injected. The photons produced in the reaction were counted on an EG\&G Berthold LB96P microplate luminometer at $30^{\circ} \mathrm{C}$. The antioxidant potential (IC50) was defined as the amount of flax extract (mg DW) that inhibits luminol chemiluminescence by $50 \%$.

\section{Preparation and biochemical analysis of flax fibers Flax retting}

Control and transgenic plants were grown in a field in the vicinity of Wroclaw and harvested after 4 months. Those plants were then retted by the dew method as described [27]. Briefly, plants were spread out in a field for at least 40 days with the plants being turned every 2 weeks. During this process, bacteria and fungi grew on the plants and caused degrading of the cell-wall polysaccharide and middle lamella. Due to this process fibers were released from the stems.

\section{Extraction of phenylopropanoids from fibers}

$1 \mathrm{~g}$ of flax fibers were grounded in a Retch mill to a fine powder and extracted trice with methanol. Extracts were pooled, evaporated under vacuum and resuspended in $2 \mathrm{ml}$ methanol.

The remaining matter was hydrolyzed in $2 \mathrm{~N} \mathrm{NaOH}$ at room temperature for $24 \mathrm{~h}$ in order to release bound phenolics. Extracts were adjusted to $\mathrm{pH} 3$, dried under vacuum and resuspended in $2 \mathrm{ml}$ of methanol.

\section{UPLC analysis of phenolics}

The components were analyzed using the Acquity UPLC system (Waters) equipped with an automated sample injector and PDA detector. A $10 \mu \mathrm{l}$ sample was applied to an Acquity UPLC HSS- T3 column $(2.1 \times 100 \mathrm{~mm}$, $1.8 \mu \mathrm{m})$ retaining better hydrophilic components. The mobile phase was passed through the column at a flow rate of $0.5 \mathrm{ml} / \mathrm{min}$. The mobile phase consisted of the following components. A: 0.1\% formic acid; and B: 100\% methanol. For the first 2 minutes, isocratic elution was carried out using $100 \%$ of A. From 2 to 5 minutes, a linear gradient was applied using 100 to $30 \%$ A in B. From 5 to 5.5 minutes, a linear gradient was applied using 30 to $0 \% \mathrm{~A}$ in $\mathrm{B}$. In the final minute concentration of $\mathrm{A}$ was returned to $100 \%$.

The additional analysis of very hydrophilic component was performed using UPLC HILIC $(2.1 \times 100 \mathrm{~mm}$, $1.7 \mu \mathrm{m}$ ) column. The mobile phase was passed through the column at a flow rate of $0.4 \mathrm{ml} / \mathrm{min}$. The mobile phase consisted of the following components. A: $0.1 \%$ formic acid; and B: $100 \%$ acetonitrile. For the first 4 minutes, isocratic elution was carried out using $10 \%$ of $\mathrm{A}$ in B. From 4 to 8 minutes, a linear gradient was applied using 10 to $90 \% \mathrm{~A}$ in B. From 8 to 9 minutes, a linear gradient was applied using 90 to $100 \% \mathrm{~A}$ in B. In the final minute concentration of eluting solvents was returned to $10 \%$ of $\mathrm{A}$ in $\mathrm{B}$.

\section{Cellulose content analysis}

Using the colorimetric method with anthron reagent, the cellulose content was determined for fibers obtained from the field-cultivated control and transgenic plants. For the sequential release of lignin, hemicelluloses and xylosans, stem samples were incubated in a mixture of 
nitric and acetic acid $\left(1: 8, \mathrm{v} / \mathrm{v}\right.$, for $30 \mathrm{~min}$ at $\left.100^{\circ} \mathrm{C}\right)$ and then centrifuged. The resulting pellet was washed twice with water $(0.5 \mathrm{ml})$ and resuspended in $1 \mathrm{ml}$ of $67 \%$ $\mathrm{H} 2 \mathrm{SO} 4(\mathrm{v} / \mathrm{v})$. After tenfold dilution with fresh anthrone reagent, and incubation at $100^{\circ} \mathrm{C}$ for $15 \mathrm{~min}$, the cellulose level was determined spectrophotometrically at $620 \mathrm{~nm}$ against cold anthrone reagent [28].

\section{Lignin content measurement}

The total lignin content in the fibers was determined via the acetyl bromide method. Lignins were isolated from fibers obtained from the field-grown control and transgenic plants. $10 \mathrm{ml}$ water was added to dried fibers (10-15 mg), and these samples were heated for $1 \mathrm{~h}$ at $65^{\circ} \mathrm{C}$ and stirred every $10 \mathrm{~min}$. Then, the samples were filtered through a GF/A glass fiber filter and rinsed with each of the following solutions: water, ethanol, acetone and diethyl ether. The filters were placed in glass vials and heated overnight at $70^{\circ} \mathrm{C}$. After that, $25 \%$ acetyl bromide

$(2.5 \mathrm{ml})$ was added to each vial, and the vials were kept at $50^{\circ} \mathrm{C}$ for $2 \mathrm{~h}$. The cooled samples were mixed with $10 \mathrm{ml}$ of $2 \mathrm{~N}$ sodium hydroxide and $12 \mathrm{ml}$ of acetic acid. The samples were left overnight, and the lignin content was analyzed by the UV method and measured at $280 \mathrm{~nm}$. Coniferyl alcohol was used to prepare a calibration curve, and the results are reported as equivalents of coniferyl alcohol [29].

\section{Determination of the pectin content}

Pectins were measured using modified method described by Melton and Smith [30]. Prior to pectin extraction the fibers were extracted with different solvent to remove the lipids and soluble sugars. The samples were washed with $96 \%$ ethanol at $100^{\circ} \mathrm{C}$, centrifuged $(5000 \times \mathrm{g}, 5 \mathrm{~min})$, and the supernatant was removed. The pellet was washed with $80 \%$ ethanol at $80^{\circ} \mathrm{C}$, and subsequently treated with mixture of chloroform and methanol (1:1 v/v). After successive centrifugation (5000 g, $5 \mathrm{~min}$ ) the pellet was washed with acetone and centrifuged once more (1000.g, $5 \mathrm{~min})$. The supernatant was discarded and the remaining pellet dried at $37^{\circ} \mathrm{C}$, frozen, and weighed. Measurement of total pectin was performed using colorimetric method after acidic hydrolysis. For hydrolysis, $100 \mu \mathrm{l}$ of concentrated sulphuric acid was added to each sample (no more than $5 \mathrm{mg}$ of dried, frozen pellet remaining after previous steps). The samples were stirred for $5 \mathrm{~min}$ at $4^{\circ} \mathrm{C}$. The volume of each sample was next adjusted to $1 \mathrm{ml}$ with distilled water in three steps $(50 \mu \mathrm{l}, 250 \mu \mathrm{l}$. and $700 \mu \mathrm{l}$ of water). The samples were stirred after each addition of water for $5 \mathrm{~min}$ at $4^{\circ} \mathrm{C}$. The pectin content was measured $7 \mathrm{spec}-$ trophotometrically at $520 \mathrm{~nm}$ using biphenyl method. Galacturonic acid was used for the calibration curve.

\section{IR spectra}

The IR spectra at room temperature were measured in the spectral range $50-4000 \mathrm{~cm}^{-1}$ using a FT-IR Biorad
$575 \mathrm{C}$ spectrometer with a $2 \mathrm{~cm}^{-1}$ resolution. The control and transgenic flax products were powdered in a automatic mortar grinder. In the mid-IR region, the samples were prepared in $\mathrm{KBr}$ pellets, and in the far-IR region, in Nujol suspension.

The mathematical deconvolution of the spectral contours into Lorenz components was made using Origin Scientific Graphing and Analysis Software in the 7.5 version.

\section{Results}

\section{Transgenic Plant Generation and Selection}

The hypocotyl and cotyledon explants of flax plants were transformed with a multigene vector containing three cDNAs encoding key enzymes of flavonoid biosynthesis, according to the Agrobacterium method [20]. The construct consisting of CHS, CHI and DFR cDNAs from Petunia hybrida under the control of CaMV 35S promoter and OCS terminator, was inserted into the genome of the flax plants [19]. The obtained regenerants were prescreened using the PCR method with specific primers for the neomycin phosphotransferase gene. Plants that exhibited a 475-bp (npt II) DNA fragment were used for further selection by means of northern blot analysis. Densitometry of northern blot revealed the significant increase of mRNA for all introduced genes compared to control and specifically for CHS 4.9 and 5.3-fold for W92.40 and W92.72 respectively; for $\mathrm{CHI}$ 5.9 and 5.4-fold for W92.40 and W92.72 respectively; and for DFR 1.16 and 1.7-fold for W92.40 and W92.72 respectively. Details on plant selection were published previously [17]. The two transgenic lines (W92.40 and W92.72) that showed the highest level of mRNA for the three introduced cDNAs were used for further analysis.

Throughout this study plants of third generation (homozygous lines) cultivated in field in a 2008 season were used. Based on PCR analysis of total RNA there were no differences in expression of three introduced genes when compared to plant of first generation (not shown). There were also no visible differences in transgenic plant phenotype when comparing to control. The leaf shape and size or petal and seed color were the same as for non-transformed plants. However, the obtained transgenic plants showed a higher productivity of seeds compared to the control plants. Transgenic plants produced $60 \%$ more seeds per ha than non-transformed plants.

\section{Biochemical analysis of seed}

For the complete analysis of seeds from field grown plant flavonoids content was determined. Our earlier experiments have shown significant changes in the level of flavanones, flavonols (kaempferol, quercetin) and 
anthocyanin in transgenic flax upon overexpression of CHS, CHI and DFR cDNAs. Therefore we analyze those compounds level in extract from seeds of F3 plant generation to verify the stability of their production.

HPLC analysis of seeds methanol extract from W92.40 and W92.72 transgenic lines reveals increase in the production of quercetin derivative (46\% and $90 \%$, respectively); moreover, analysis reveals increase in kaempferol derivative accumulation in seeds by about $70 \%$ in line W92.40 and 83\% in line W92.72( Figure 1).

Since the third gene in our transgenic construction was $D F R$, the product of its activity (anthocyanins) was also measured. We found an increase in antocyanins level of about 198\% in the seeds (for line W92.40 and W92.72 -197\% and 199\%, respectively).(Figure 1).

Flavonoids were shown to exhibit antioxidant properties [11]. Very important for health promoting properties of flax seeds are lignans which are known as effective anti-cancer factor. The level of a main flax lignan, secoisolariciresinol diglucoside (SDG)was more than two times higher in lines W92.40 and W92.72. Since there was an increase in the total phenolic compounds detected in transgenic plants, an increase in antioxidant capacity was expected. The antioxidant properties of flax seeds extract were assessed via the chemiluminescence method, as described previously [31]. The antioxidant potential is expressed as the

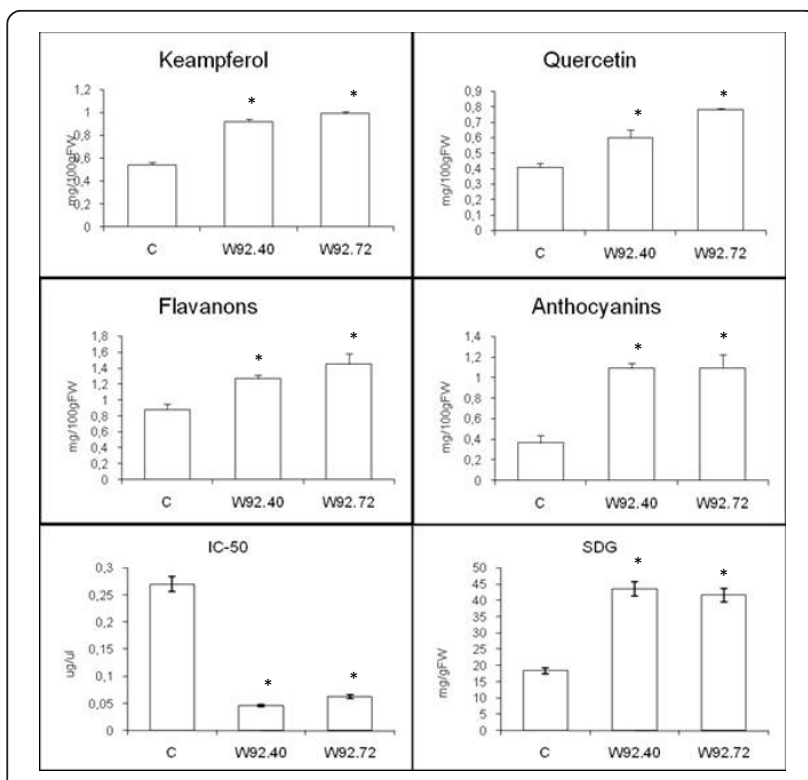

Figure 1 Biochemical analysis of seeds. The content of kaempferol and quercetin glycoside. total anthocyanins, flavanons and SDG content in seeds from control (C) and the transgenic flax plants (numbered). The antioxidant activity of plant extracts is presented as IC-50 parameter. The mean value $(n=6) \pm$ SD for seeds from plant cultivated in a field is presented. *Statistically significant $(P<0.05)$.
$\mathrm{IC}_{50}$ value, which means the amount of seed extract inhibiting the oxidation of luminol by $50 \%$. The antioxidant properties of the seeds of transgenic plants were higher than those of the non- transformed plant. The 6 -fold increase of antioxidant capacity in line W92.40 and 4-fold in line W92.72 was observed. Figure 1 shows the antioxidant level of the seed extract from transgenic and control plants. This data indicates that the antioxidative status of the transgenic plants mainly resulted from the activation of the flavonoid biosynthesis pathway, through the overexpression of the three key flavonoid genes.

The overall conclusion that can be drawn from biochemical analysis of transgenic seeds is that after three seasons (2006-2008) of plant cultivation in field the level of producing compounds as the result of three genes overexpression is stable. Thus it is suggested that introduced Petunia genes into the flax are stably inherited and expressed.

\section{Preparation of oil from seeds}

The seeds from plant field grown in the 2008 season were used as a source of oil. The oil was produced by typical industrial method including seeds grounding and cold pressing. There was no difference in the yield of oil from control and transgenic seeds and in both cases was about $25 \%$.

\section{Biochemical analysis of oil from seeds}

The objective of this work was to analyze fatty acids content and composition, tocopherols, plastochromanol8 and $\beta$-carotene as the known flax compounds with chemotaxonomic significance [24]. For fatty acids composition and quantity the flaxseed oil was examined by gas chromatography equipped with FID (flame ionization) detector. Tocopherols, plastochromanol-8 and $\beta$-carotene were assayed by HPLC analysis.

It was expected that overproduction of flavonoids in plant might improve the fatty acids composition in seeds. Indeed the data presented in Table 1 shows the increase in the content of fatty acids in oil. The increase in unsaturated 18:1 (6\%), 18:2 (38-49\%) and $18: 3(48-61 \%)$ fatty acids in both transgenic lines was detected. The highest increase was measured in W92.40 transgenic line.

Beside composition the higher accumulation of all fatty acids in transgenic seeds when compared to the control was observed. The $31 \%$ and $40 \%$ increase of total fatty acids content in oil from transgenic plant W92.40 and W92.72, respectively, compared to the control. Thus it is suggested that accumulation of flavonoids in flax reasonably affect the fatty acids production in seeds.

The next step in oil analysis was assessment of its stability. Level of lipid oxidation stability was determined 
Table 1 Fatty acids composition of oil from Linola (control) and transgenic seeds (W92.40 and W92.72) expressed in $\mu \mathrm{g} / \mathrm{gFW}$

\begin{tabular}{|c|c|c|c|c|c|c|c|c|c|c|c|c|c|c|}
\hline & 16:0 & $16: 1$ & $16: 2$ & $16: 3$ & 18:0 & 18:1 & $18: 2$ & $18: 3$ & $20: 0$ & $20: 1$ & 22:0 & 22:1 & 24:0 & Total \\
\hline Linola & $\begin{array}{l}11.33 \pm \\
1.8\end{array}$ & $\begin{array}{l}0.16 \pm \\
0.05\end{array}$ & $\begin{array}{l}0.12 \pm \\
0.04 \\
\end{array}$ & $\begin{array}{l}0.10 \pm \\
0.0 \\
\end{array}$ & $\begin{array}{l}6.38^{*} \pm \\
0.8\end{array}$ & $\begin{array}{l}32.57 \pm \\
1.8\end{array}$ & $\begin{array}{l}158.57^{*} \pm \\
11.3\end{array}$ & $\begin{array}{l}3.64 \pm \\
1.8 \\
\end{array}$ & $\begin{array}{l}0.26 \pm \\
0.1 \\
\end{array}$ & $\begin{array}{l}0.19 \pm \\
0.4 \\
\end{array}$ & $\begin{array}{l}0.12 \pm \\
0.3 \\
\end{array}$ & $\begin{array}{l}0.10 \pm \\
0.0\end{array}$ & $\begin{array}{l}0.03 \pm \\
0.0\end{array}$ & $\begin{array}{l}213.57 \pm \\
22.8\end{array}$ \\
\hline W92.40 & $\begin{array}{l}14.68^{*} \pm \\
1.5\end{array}$ & $\begin{array}{l}0.27 \pm \\
0.02\end{array}$ & & $\begin{array}{l}0.15 \pm \\
0.0\end{array}$ & $\begin{array}{l}7.32^{*} \pm \\
0.5\end{array}$ & $\begin{array}{l}34.55^{*} \pm \\
1.3\end{array}$ & $\begin{array}{l}236.55^{*} \pm \\
9.4\end{array}$ & & $\begin{array}{l}0.16 \pm \\
0.1\end{array}$ & & & & $\begin{array}{l}0.05 \pm \\
0\end{array}$ & $\begin{array}{l}300.42^{*} \pm \\
18.6\end{array}$ \\
\hline N92.72 & $\begin{array}{l}13.75^{*} \pm \\
0.9\end{array}$ & $0.26 \pm$ & & $\begin{array}{l}0.12 \pm \\
0.0\end{array}$ & $\begin{array}{l}6.49 \pm \\
0.4\end{array}$ & $\begin{array}{l}34.65^{*} \pm \\
1.5\end{array}$ & $\begin{array}{l}218.51^{*} \pm \\
15.1\end{array}$ & $\begin{array}{l}5.39^{*} \pm \\
1.4\end{array}$ & $\begin{array}{l}0.18 \pm \\
0.1\end{array}$ & $\begin{array}{l}0.29^{*} \pm \\
0.5\end{array}$ & $\begin{array}{l}0.13 \pm \\
0.5\end{array}$ & $\begin{array}{l}0.15 \pm \\
0.0\end{array}$ & $\begin{array}{l}0.05 \pm \\
0\end{array}$ & $\begin{array}{l}280.14^{*} \pm \\
21.8\end{array}$ \\
\hline
\end{tabular}

The mean value $(n=6) \pm$ SD for oil from plant cultivated in a field is presented.*Statistically significant $(P<0.05)$

by by measuring peroxide value (level of prime products of lipid peroxidation) and TBARS (indication of malonic dialdehyde - MDA the one of secondary products of lipid peroxidation) ( Figure 2). The TBARS measurements shows decrease by about $80 \%$ and $40 \%$ for oil from lines W92.40 and W92.72, respectively, when compared to control. Also peroxide value is slightly lower for transgenic plant.

Since the flavonoid biosynthesis pathway is separated from fatty acids metabolism, perhaps the way by which the last is activated upon CHS, CHI and DFR overexpression comes from nonspecific antioxidative function of flavonoids. In other words accumulated antioxidative compounds in transgenic seeds partially extract with oil and thus might protect fatty acids against oxidation. The question appeared whether the antioxidants accumulate in oil from transgenic seeds. For that reasons we measured the compound content that might protect fatty acids in oil against oxidation ( Table 2). There was slight but not significant difference in antioxidants level in oil from transgenic seeds compared to control. Even so the stability of oil from transgenic plant is improved. Thus the final conclusion is that fatty acids metabolism changes in transgenic seeds resulted from their protection during synthesis and seed maturation. This conclusion is an agreement with the in vitro studies, where unsaturated fatty acids were protected against oxidation when supplied with micromolar concentration of exogenously added quercetin or $\beta$-carotene [32].
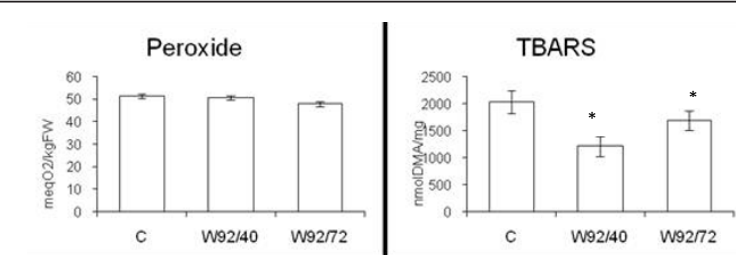

Figure 2 Antioxidant potential of oil. The peroxide value, TBARS in heated oils from control(C) and transgenic plants (numbered). The mean value $(n=6) \pm$ SD for oil from plant cultivated in a field is presented. *Statistically significant $(P<0.05)$

\section{Biochemical analysis of seedcake extract}

Since the changes in fatty acids composition and yield of oil were detected it was reasonable to analyze the residual seed tissues (seedcake) after oil pressing. It was expected an accumulation of antioxidants from flavonoid pathway in seedcakes and thus protection of fatty acids. The analysis was conducted on similar methanol extract as it was performed for seeds. The data presented in Figure 3 shows the significant increase of flavanones and flavonols as well as anthocyanins level. Similar to seed extract, the flavanone content in seedcake extract from W92.40 and W92.72 plant was increased by $53 \%$ and $55 \%$, respectively. Also the flavonols level significantly increased in seedcake extract from transgenic lines and was $72 \%$ and 85\% higher for W92.40 and W92.72, respectively, when compared to control.

We observe about three fold increase of the anthocyanin level in both transgenic lines compared to control.

As a result of flavonoids increase the antioxidant capacity increased significantly (IC50 decrease). The IC50 parameter for seedcake extract from transgenic lines was over 6-fold lower than for control plant. Since this parameter might be also affected by the compounds not extracted with methanol we have decided to analyze antioxidative metabolites in seedcake after alkali hydrolysis. To our surprise UPLC analysis of alkali hydrolyzed seedcake from transgenic plant reveals significant increase of phenolic acids and lignans when compared to control (Figure 4). Of several peaks in UPLC chromatogram we were able to identify coumaric acid and ferulic/synapic acids based on retention time and UV spectra of respective standards. The last might contains ferulic acid and also synapic acid since at chromatographic condition used, retention time of both is quite close (3.376 for ferulic and 3.396 for synapic acids) and their spectra are very similar.

Since phenolic acids (e.g. coumaric) are the precursor of lignan synthesis we have also measured this compound in alkali hydrolyzed extract. It was found that the seedcake extract from transgenic plant show 4.3 fold and 3.8 fold higher secoisolariciresinol diglucoside (SDG) content in transgenic lines W92.40 and W92.72, respectively. Secoisolariciresinol aglycone (4.5 retention 
Table 2 Antioxidants content in flax oil from Linola (control) and transgenic seeds (W92.40 and W92.72) expressed in $\mathrm{mg} / 100 \mathrm{gFW}$

\begin{tabular}{lllll}
\hline & $\begin{array}{l}\text { Phenolic } \\
\text { compounds }\end{array}$ & Tocopherols & $\begin{array}{l}\text { Plastochromanol- } \\
\mathbf{8}\end{array}$ & $\begin{array}{l}\boldsymbol{\beta} \text { - } \\
\text { carotene }\end{array}$ \\
\hline Linola & $1.19 \pm 0.04$ & $83.37 \pm 0.61$ & $11.48 \pm 0.07$ & $0.14 \pm$ \\
& & & & 0.01 \\
\hline W92.40 & $1.27^{*} \pm 0.01$ & $83.56 \pm 0.72$ & $13.18^{*} \pm 0.40$ & $\begin{array}{l}0.16^{*} \pm \\
0.01\end{array}$ \\
\hline W92.72 & $1.35^{*} \pm 0.01$ & $81.15^{*} \pm 0.13$ & $11.85 \pm 0.21$ & $0.15^{*} \pm$ \\
& & & & 0.01 \\
\hline
\end{tabular}

The mean value $(n=6) \pm$ SD for oil from plant cultivated in a field is presented. *Statistically significant $(P<0.05)$

time) was also identified only a trace amount compared to SDG quantity was detected (not included in chromatogram).

Phenolic acids and lignans likelihood flavonoids are the main constituents of phenylpropanoid pathway. In view of the presented results there should be operating mechanism of their biosynthesis coregulation based perhaps on substrate availability or prooxidative function of accumulated antioxidants which is discussed in Discussion section.

\section{Flax retting and fiber isolation}

Retting is the process by which linen fibres are obtained. In this process, bast fibre bundles are separated from the core, the epidermis and the cuticle. This is accomplished by the cleavage of pectins and hemicellulose in

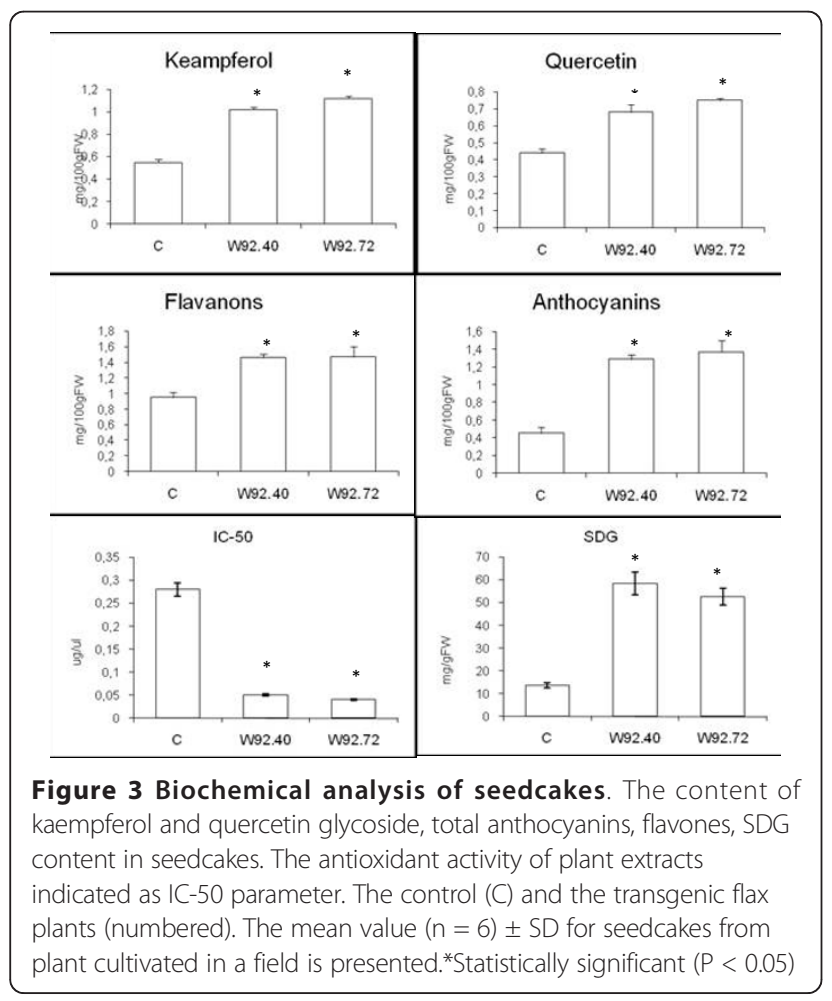

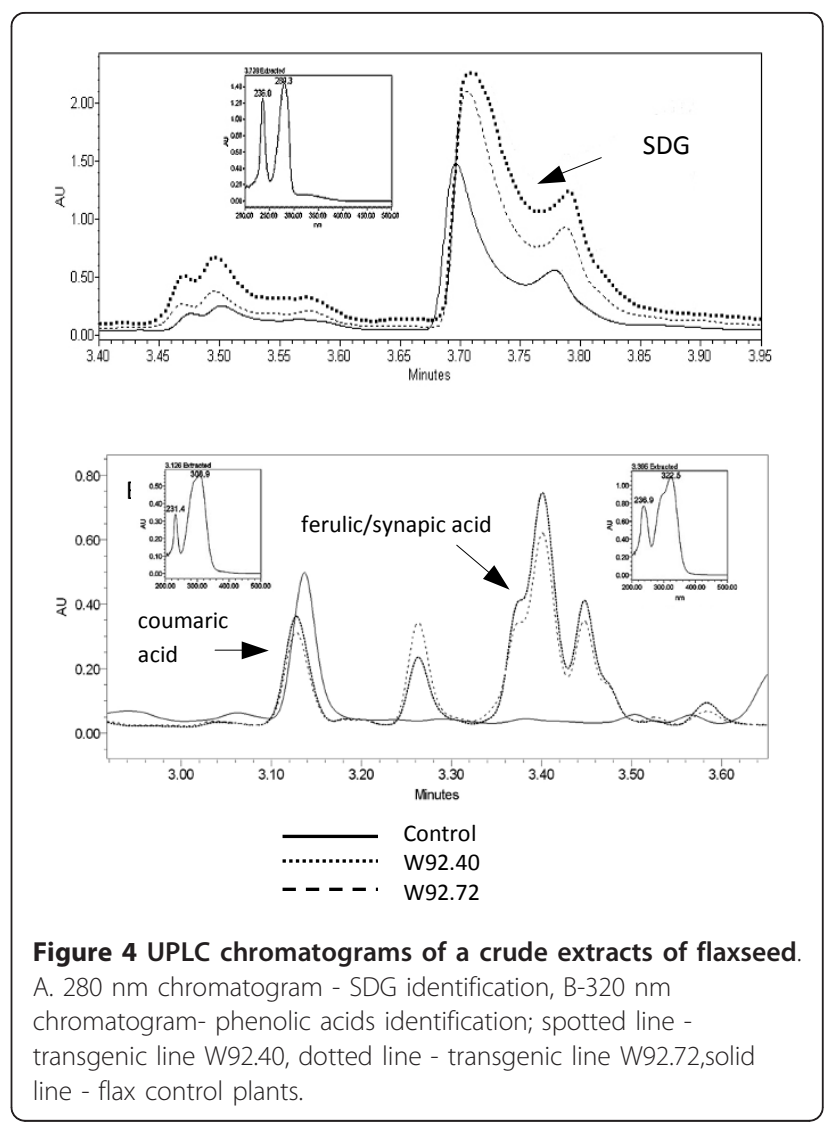

the flax cell wall, mainly due to the action of plant pathogens. For a high quality of fibre, the proper degree of retting is crucial $[33,34]$ Thus, the efficiency of retting was carried out by scanning electron microscopy (SEM). The SEM of fibres depicted in Figure 5 indicates that retting process is not fully completed in both control and transgenic fibres. The elementary fibres stick together and non-fibrous tissue and cuticle fragments are still present however in case of transgenic fibres the retting is more advanced. The reasons for this could be either the reduction in the pectin content or degree of lignifications or a different arrangement of lignocelluloses polymers in transgenic fibres. In order to verify these suggestions biochemical and spectral analysis of fibres was performed.

Biochemical analysis of fibers

Cellulose is the basic structural component of flax fibres. The other important component for fibre structure is lignin, which provides rigidity to the plant. Incrustation of the cell wall by lignin hardens it and reduces its water content, which results in a lower elasticity. Pectins, the other fibre constituents, are mainly responsible for binding single fibres into bundles, and are predominantly released during retting. However, they are also present in the primary wall of individual 


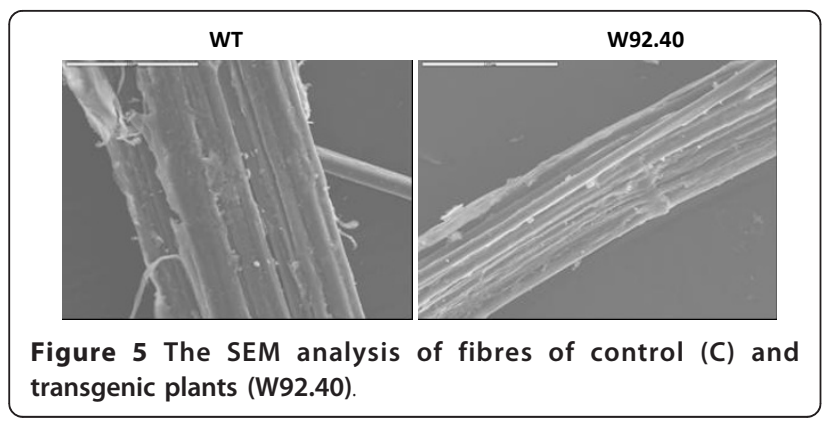

fibres, and therefore are constituents of the fibres themselves [33]. We determined the content of these compounds in transgenic flax fibres and compared them to the contents for the control fibres. There were no changes in cellulose and pectin compounds content and slight decrease in lignin content compared to fibres from control plants (Table 3). Although the lignin content was lower in transgenic fibres there was no visible changes in scanning electron microscopy of transgenic fibres compared to control (Figure 5).

Since the dramatic changes in flavonoid compounds content in seeds, oil and seedcakes from transgenic plant were detected it was reasonable to analyze the fibers which is also valuable product of flax plant. For the construction of transgenic plants the strong and nonspecific $35 \mathrm{~S}$ CaMV promoter was used, which resulted in changes occurring in whole plant body. It was expected an accumulation of antioxidants from phenylpropanoid pathway also in fibres. The analysis was as first conducted on methanol extract similarly to this performed for seeds. The data presented in Figure 6 indicate the presence of compounds which can be fairly well identified as derivatives of syringaldehyde and catechine based on retention time and UV spectra and the level of last is lower in transgenic fibres when compared to control. The highest peak in the UPLC chromatogram (P1) showed the UV spectra very similar to coumaric acid/syringic acid standards but their retention time is significantly moved toward lower RT. Thus HILIC chromatography has been applied to separate the constituents of this peak. The HILIC chromatography

Table 3 Fibre components content in flax fibre Linola (control) and transgenic (W92/40 and W92/72) in ug/ mgDW

\begin{tabular}{llll}
\hline & Cellulose & Pectin & Lignin \\
\hline Linola & $578.87 \pm 48.8$ & $0.025 \pm 0.002$ & $2.13 \pm 0.04$ \\
\hline W92/40 & $552.42 \pm 39.5$ & $0.024 \pm 0.001$ & $1.72^{*} \pm 0.02$ \\
\hline W92/72 & $622.46^{*} \pm 5.51$ & $0.025 \pm 0.001$ & $1.76^{*} \pm 0.016$
\end{tabular}

The mean value $(n=6) \pm$ SD for oil from plant cultivated in a field in 2008 is presented.*Statistically significant $(P<0.05)$

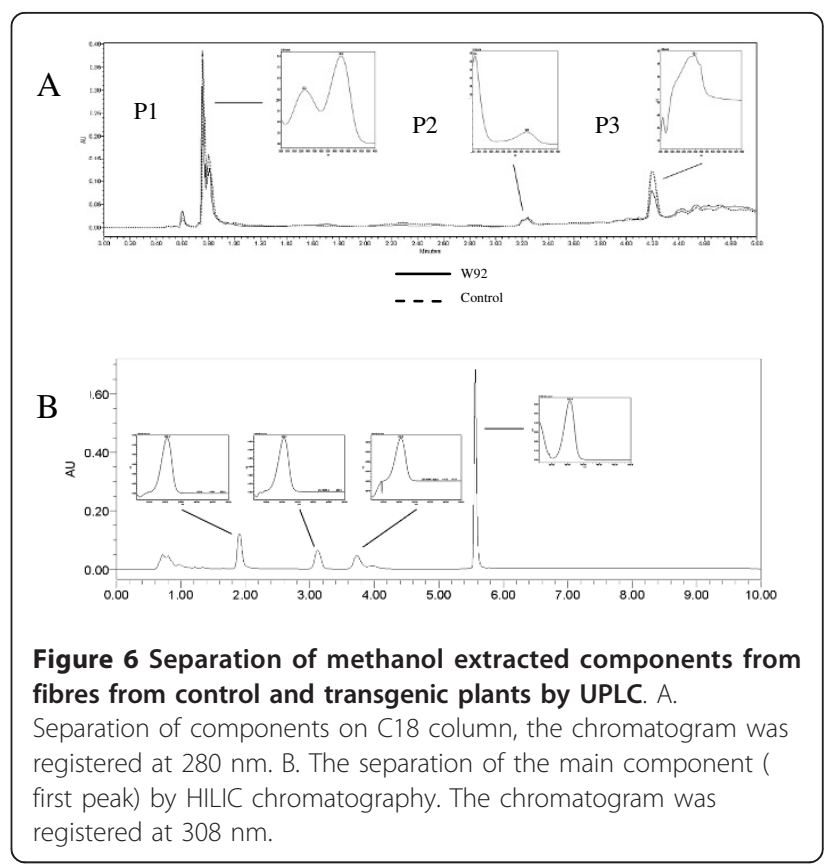

indicates four peaks and the highest showed UV spectrum identical with syringic acid standard and other three typical for coumaric acid standard. In all cases the retention time however does not fit to the respective standards. Therefore it is suggested that coumaric and syringic derivatives as well as catechine are the main constituents of flax fibres methanol extract and their content in transgenic fibres are lower than in case of fibres from control plant. The HILIC chromatography does not separate catechine and syringaldehyde which localizes at $0.8 \mathrm{~min}$ RT.

For the complete analysis of fibres their alkali hydrolysis was performed which might allow us to identify and analyze the compounds bound to cell well. The result of UPLC analysis of alkali treated fibres is presented in Figure 7 . The analysis basically revealed the presence of the same compounds that have been found in fibre methanol extract. However the level of catechine is

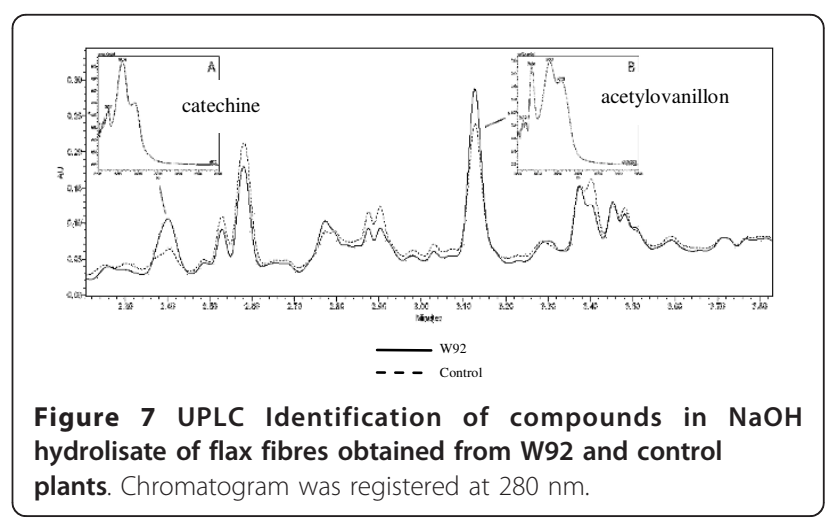


almost two fold higher in fibre from transgenic plant compared to control. Acetylovanillone is the compound that has been found only in fibre alkali hydrolyzed and its level appeared to be higher in transgenic fibres when comparing to control. The level of phenolic acid (ferulic) in hydrolyzed fibre from transgenic plant is lower than from control.

Since the biochemical analysis of oil, seedcake extract from transgenic seed and fibres reveals the presence of valuable compounds it was of interest from biotechnological point of view to perform detailed structural analysis of those product. In order to do these FT-IR studies of flax products was conducted.

\section{Infrared study of flax products}

Biochemical studies of oil, seedcake extract and fibre from transgenic flax revealed the changes in level and composition of fatty acids in oil and presence of several compounds of phenylpropanoid origin (kaempferol, coumaric and ferulic/synapic acids, lignans) that were overproduced upon plant transformation with three key genes of this pathway. The significant increase in the quantity of phenolic acids and lignans was detected. In order to verify this data and expand compounds identification IR analysis of flax products were conducted.

The presented assignments of bands to the respective normal modes have been performed by comparison of our own results with published vibrational spectra of the respective standards molecule [35-39]. All spectra were characterized by bands wavenumber and band intensity

It should be noted that the spectra of all analyzed products (oils and seedcake extracts and fibres) from control and transgenic plant were recorded at the same conditions, i.e. using the same dishes, transmission windows and distance washers.

\section{IR spectra of oil}

The IR spectra of oil from control and transgenic plant has been recorded (Figure 8) and compared to the standard molecules spectra. Their detailed analysis has been performed in our previous paper [40]. The spectra of oil have been integrated to the maxima of the bands at 2928 and $1747 \mathrm{~cm}^{-1}$. The former corresponds to the $v_{\mathrm{as}}$ $\left(\mathrm{CH}_{2}\right)$ and the later to the $v(\mathrm{C}=\mathrm{O})$ stretching vibrations. They are characteristic for the glycerol ester of the fatty acids and the intensities of these bands can be used as reference points for the IR studies. This approach allows for quantitative comparison of bands intensities in the spectra of oil isolated from control and transgenic plant.

The IR spectra of oil from control and transgenic plant are similar both in respect to the wavenumbers and intensities of the strongest bands. However, the

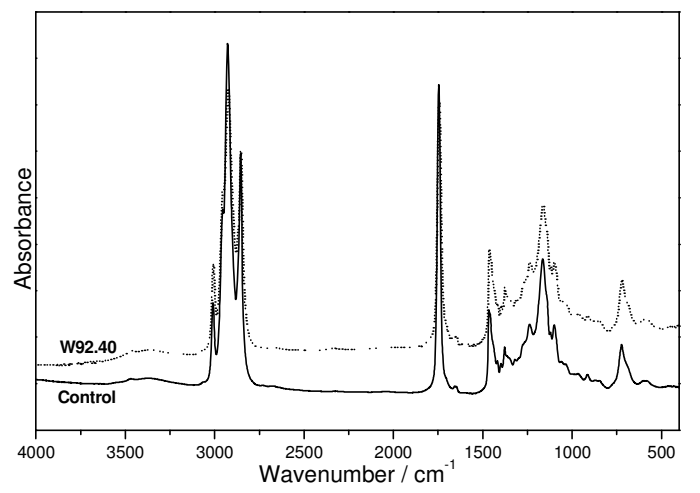

Figure 8 The IR spectra of the flaxseeds oils obtained from the natural Linola (control) flax and transgenic W92.40.

contours observed for the oil from transgenic plant are broader and contain several additional components.

The differences between the IR spectral contours of oil from control and transgenic flax become evident when very weak bands in some regions are multiplied by factor ten (Figure 9a). All bands of IR contour in the region $1500-1680 \mathrm{~cm}^{-1}$ exhibit higher intensity for the transgenic sample. Furthermore the band detected at about $1650 \mathrm{~cm}^{-1}$ for the control oil splits into two components at 1648 and $1657 \mathrm{~cm}^{-1}$ for transgenic sample. These bands can be assigned to the $v(C=C)$ vibrations. In particular, the later component can be assigned to the $v(C=C)$ vibration in synapic acid, ferulic acids and kaempferol because their respective bands for standards

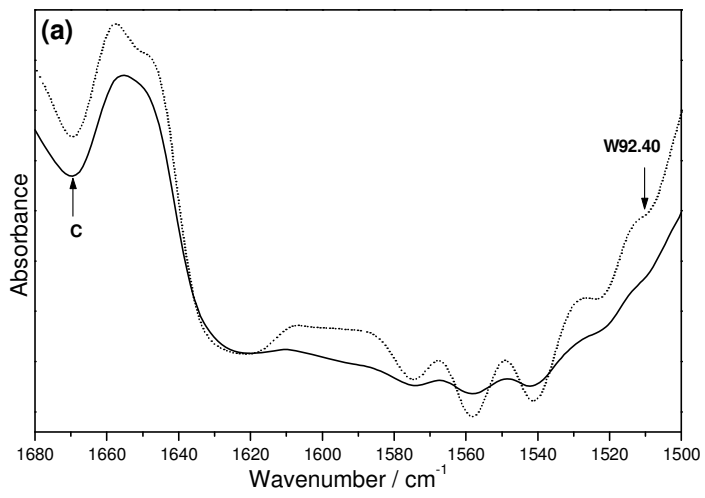

Figure 9 The IR contours from the region $1500-1680 \mathrm{~cm}-1$ of oils from control(C) and transgenic (W92.40) flax plants. The $1657 \mathrm{~cm}-1$ component is assigned to the $v(C=C)$ vibration in synapic acid, ferulic acids and kaempferol. The band at $1608 \mathrm{~cm}-1$ fits to standard spectra for secoisolariciresinol (SECO),

secoisolariciresinol diglucoside (SDG) and coumaric acid. The 1589 cm-1 band is characteristic for ferulic, coumaric and synapic acids. Bands at $1567 \mathrm{~cm}-1$ correspond to kaempferol, at $1512-1515 \mathrm{~cm}-1$ to the SECO, SDG and coumaric acid and $1517 \mathrm{~cm}-1$ to synapic acid and SECO. 
appear at 1663, 1664 and $1662 \mathrm{~cm}^{-1}$, respectively. Similar coincidence is observed for the other bands of this region in the spectra of oils. The band at $1608 \mathrm{~cm}^{-1}$ fits well to those observed at 1601, 1604 and $1602 \mathrm{~cm}^{-1}$ for secoisolariciresinol (SECO), secoisolariciresinol diglucoside (SDG) and coumaric acid, respectively and those at $1589 \mathrm{~cm}^{-1}$ correspond to bands at 1591, 1589 and $1583 \mathrm{~cm}^{-1}$ characteristic for ferulic, coumaric and synapic acids, respectively. Bands at $1567 \mathrm{~cm}^{-1}$ correspond to $1569 \mathrm{~cm}^{-1}$ of kaempferol and those at $1512 \mathrm{~cm}^{-1}$ to the $1515 \mathrm{~cm}^{-1}$ of SECO, $1516 \mathrm{~cm}^{-1}$ of SDG, $1512 \mathrm{~cm}^{-}$ 1 of coumaric acid, $1517 \mathrm{~cm}^{-1}$ of synapic acid and $1517 \mathrm{~cm}^{-1}$ of SECO. These bands are stronger for transgenic sample suggesting the higher content of these compounds in transgenic plant. Biochemical analysis of total phenolic compounds in oil from transgenic plant also suggests their slightly increased level compared to control. Thus the data from IR analysis confirms these from biochemical estimation. Additionally IR spectra analysis helps to identified phenolic constituents of oil which is not possible in biochemical analysis. Therefore it is suggested that IR analysis of oil provides important information on oil characteristic.

The overall conclusion from the IR study of oil is that several compounds of hydrophilic nature passed to the oil upon seed treatment with high pressure under low temperature. Among those compounds are flavonoids, phenolic acids and lignans. Although we are not able to quantify those compounds it is quite clear that their level is higher in oil from transgenic seed when compared to control. The detection of compounds of phenylpropanoid pathway in oil appears to be a good molecular background for protection of fatty acids from transgenic oil against oxidation which was the case as measured in TBARS method.

\section{IR spectra of seedcake extract}

The UPLC analysis of seedcake extract has shown the presence of several compounds with antioxidant activity originated from phenylpropanoid pathway. Among these compounds kaempferol, coumaric, ferulic/synapic acids and lignans were detected. The higher quantity of these compounds in seedcake extract from transgenic plant compared to control was also detected. In order to verify these data IR spectra of seedcake extracts was recorded and compared to respective standard molecules. The spectrum of seedcake extract revealed several bands and they can be grouped into five clear contours that appear in the regions 2000 - 3750, 1580 - 1800, 1310 - 1350, $950-1530$ and $400-850 \mathrm{~cm}^{-1}$ (Figure 10). The contours from the second, fourth and fifth regions emerges vibrations of characteristic groups of phenolic acids, flavonoids and lignans and thus have been deconvoluted into Lorenzian components (Figure 11).
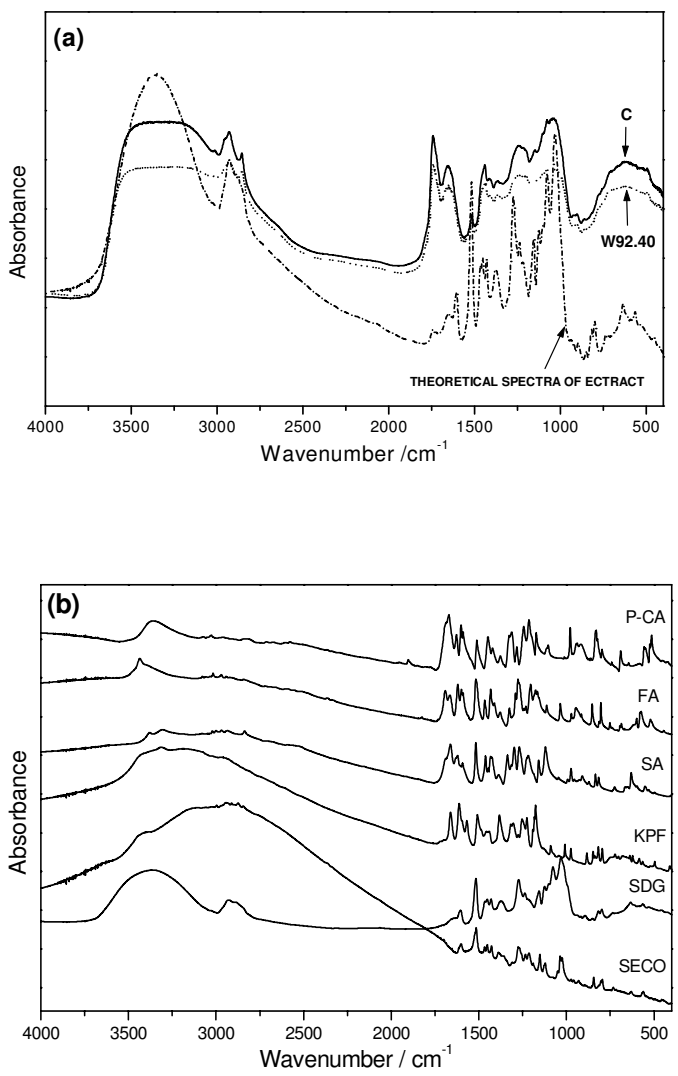

Figure 10 The IR analysis of seedcake extracts. The IR spectra of the (a) seedcake extracts obtained from the control(C) and transgenic (W92.40) flax plants; (b) The IR spectra of standards: seicoisolarisiresinole (SECO), seicoisolarisiresinol diglucoside (SDG), kaempferol (KPF), sinapic acid (SA), ferulic acid (FA), p-coumaric acid (P-CA)

Comparing intensity and bandwidth of the bands derived from the deconvoluted contours it is seen that several components have significantly higher intensity and bandwidth for the seedcake extract from transgenic seeds. Beside, some of these bands change their energetic position. Such changes appear for the IR components with the maximum at 1678, 1262, 1231, 657 and $614 \mathrm{~cm}^{-1}$. These wavenumbers agree well with the strong intensity bands observed in the IR spectra for the standard molecules. It concerns the following bands:

- $1678 \mathrm{~cm}^{-1}$ that coincides with the strong bands at 1686 and $1671 \mathrm{~cm}^{-1}$ of the coumaric acid,

- $1261 \mathrm{~cm}^{-1}$ that coincides with the strong bands at 1266 and $1275 \mathrm{~cm}^{-1}$ of SECO, $1273 \mathrm{~cm}^{-1}$ of SDG and $1277 \mathrm{~cm}^{-1}$ of the ferulic acid,

- $657 \mathrm{~cm}^{-1}$ that agrees with the bands at $667 \mathrm{~cm}^{-1}$ of the ferulic acid,

- $614 \mathrm{~cm}^{-1}$ that corresponds to the bands observed in the region of SDG, coumaric and ferulic acids and kaempferol. 

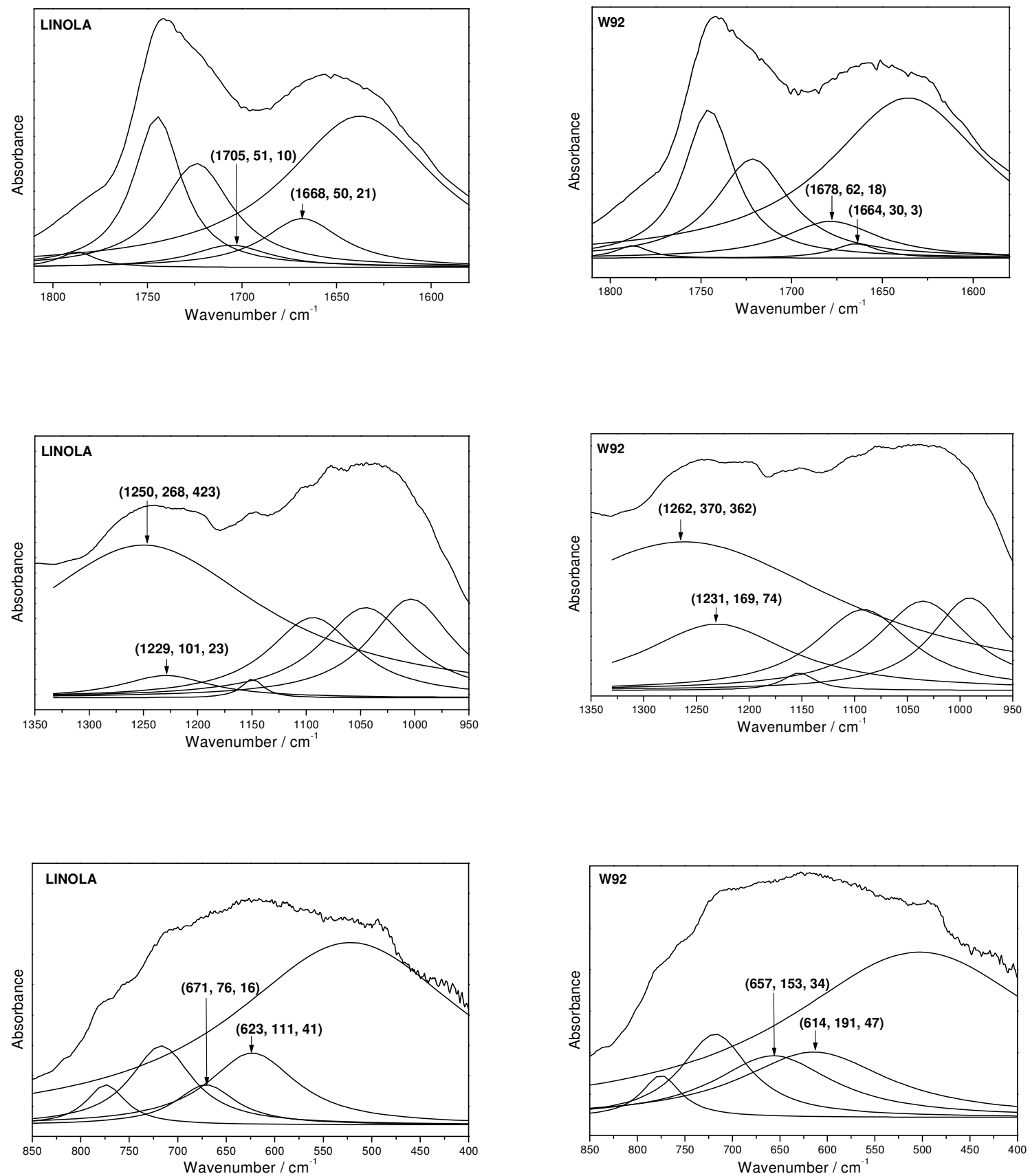

Figure 11 The deconvolution of the IR contours of control and transgenic (W92) seedcakes extracts. The deconvolution of the IR contours of control and transgenic (W92) seedcakes extracts in the regions: $1580-1800,950-1350$ and $400-850 \mathrm{~cm}^{-1}$ into Lorenz components. The energetic positions, of the components with differ for the GM and natural flax are given in the parentheses. The $1678 \mathrm{~cm}^{-1}$ band assigned to coumaric acid, $1261 \mathrm{~cm}^{-1}$ band assigned to SECO, $1273 \mathrm{~cm}^{-1}$ to SDG and $1277 \mathrm{~cm}^{-1}$ and $657 \mathrm{~cm}^{-1}$ bands assigned to ferulic acid, and $614 \mathrm{~cm}^{-1}$ that correspond to the bands observed in the region of SDG, kaempferol, coumaric and ferulic acids.

The observed changes in the energetic position of bands characteristic for phenylpropanoids compounds in IR spectrum of seedcake extract from transgenic seed compared to control confirm the higher content of these compounds in extract from transgenic seedcake which was detected by UPLC analysis. Thus the conclusion is that the extract from transgenic seedcake contains the same phenylpropanoid compounds that were identified by UPLC analysis and they are in higher quantity when compared to control. Further the IR 
spectra were helpful in identification of phenolic acids (ferulic vs. synapic) which was impossible in UPLC analysis. Thus the IR spectra are suitable for detailed compounds analysis of seedcake extract.

\section{IR spectra of fibres}

FT-IR spectroscopy has been found to be very suitable to detect the major chemical components of flax stems in vivo [41]. The technique was also found to provide information on the molecular changes in flax fibres caused by ageing [42], mechanical processing and chemical treatment $[36,43]$. Therefore, the molecular characteristic of the fibres was further verified by IR spectroscopy.

Figure 12a shows the IR Fourier spectra of fibres isolated from the control and transgenic plants. The broad absorption band at $3400 \mathrm{~cm}^{-1}$ corresponds to the stretching $v \mathrm{OH})$ mode of the free hydroxyl groups and those involved in the intra- and inter-molecular hydrogen bonds. The shape of this band is nearly the same for all the samples studied (i.e. the control and transgenic fibres) and very similar to that for purified cotton cellulose, but the bands differ in terms of their absorption intensity. The band could be deconvoluted into four Lorenzian components (Figure 12b) at $3460\left(\mathrm{I}_{(1)}\right)$, $3410\left(\mathrm{I}_{(2)}\right), 3350\left(\mathrm{I}_{(3)}\right)$ and $3300\left(\mathrm{I}_{(4)}\right) \mathrm{cm}^{-1}$. The number of components concurs with that expected for the four hydroxyl types of the $\beta$-D-glucopyranosyl polymer, which contains three hydroxyls in the glucopyranose ring and one hydroxyl group at the ends of the chains. The integral intensity of these components for the control flax fibres changes in the following direction $\mathrm{I}_{(3)}>$ $\mathrm{I}_{(2)}>\mathrm{I}_{(1)}>\mathrm{I}_{(4)}$ and for transgenic fibres W92.40 and W92.72: $\mathrm{I}_{(3)}>\mathrm{I}_{(2)}>\mathrm{I}_{(4)}>\mathrm{I}_{(1)}$ and $\mathrm{I}_{(2)}>\mathrm{I}_{(4)}>\mathrm{I}_{(3)}>\mathrm{I}_{(1)}$, respectively. The overall intensity of all the components for the investigated samples follows the direction $\mathrm{I}_{\text {Control }}$ $>\mathrm{I}_{\mathrm{W} 92.72}>\mathrm{I}_{\mathrm{W} 92.40}$. The changes in the intensity of the $3400 \mathrm{~cm}^{-1}$ band components for the control and transgenic fibres probably resulted from different conformations of the intramolecular and intermolecular hydrogen bonds $\mathrm{O}-\mathrm{H} \mathrm{O}$ of the glucopyranose system.

Such changes are expected when different rotary isomers appears in the skeleton of the cellulose polymer, since they differ in the strength and orientation of the hydrogen bond. This leads to the disordered arrangement of the pyranoid rings in the cellulose polymers in fibres from transgenic flax. It should be pointed out that opposite effect has been observed for fibres from transgenic flax producing polyhydroxybutyrate. In this case the intensity of $3400 \mathrm{~cm}^{-1}$ band components was significantly higher than those for control fibres $[44,45]$.

It has commonly been accepted that the most diagnostic regions that characterize the pectin and lignin constituents of fibres is $1400-1800 \mathrm{~cm}^{-1}$ region of IR spectra. The bands in this region of IR spectra for control and transgenic W92.40 and W92.72 flax fibres could be deconvoluted into five Lorenzian components that approximate well the envelope of these contours.

The component at about $1736 \mathrm{~cm}^{-1}$ corresponds to the $v_{\mathrm{as}}(\mathrm{COO})$ vibrations of unconjugated carboxyl group of pectins. The relative intensity of this band fulfills the relations: $\mathrm{I}_{\mathrm{c}}<\mathrm{I}_{72}<\mathrm{I}_{40}$ showing the irregular dependence on the pectin content $\left(\mathrm{I}_{40}\right.$ was expected to be smaller than $\mathrm{I}_{72}$ ), although the GM samples exhibit somewhat their greater content. The position of band at $1662 \mathrm{~cm}^{-}$ ${ }^{1}$ is characteristic for lignins and its intensity increases for W92.40 and W92.72. This band has been considered as originating from both protein impurity and water associated with lignin [46]. The irregular trend is observed for the band at $1642 \mathrm{~cm}^{-1}$ that corresponds to the $v_{\text {as }}(\mathrm{COO})$ vibration of the conjugated carboxyl group. Its intensity clearly increases for the W92.40 but decreases for W92.72 samples. On the other hand, the bands at 1608 and $1504 \mathrm{~cm}^{-1}$ show regular behavior i.e. $\mathrm{I}_{\mathrm{c}}>\mathrm{I}_{40}>\mathrm{I}_{70}$ but their integral intensities are practically very close. They correspond to the stretching vibrations of the aromatic skeleton of the lignins [46].The contours observed in the IR spectra of the flax fibres in the regions $1200-1500,950-1200 \mathrm{~cm}^{-1}$ and $500-950 \mathrm{~cm}^{-}$ ${ }^{1}$ are typical for the flax cellulose consisting of some amounts of lignins and pectins (Figure 13). The bands from these multiplets can be assigned to the vibration of $\delta_{\text {as }}\left(\mathrm{CH}_{3}, \mathrm{CH}_{2}\right)$ at $1429 \mathrm{~cm}^{-1}, \delta_{\mathrm{s}}\left(\mathrm{CH}_{3}, \mathrm{CH}_{2}\right)$ at $1372 \mathrm{~cm}^{-1}$, $\delta(\mathrm{CH})$ at 1319 and $1336 \mathrm{~cm}^{-1}, v(\mathrm{C}-\mathrm{C})$ and $v(\mathrm{C}-\mathrm{O})$ at the range from 1200 to $1300 \mathrm{~cm}^{-1}, \delta(\phi-\mathrm{OH})$ at $1163 \mathrm{~cm}^{-1}$, $v_{\mathrm{as}}(\mathrm{C}-\mathrm{O}-\mathrm{C})$ at the range of $1000-1110 \mathrm{~cm}^{-1}, \gamma(\mathrm{CH})$ at the range of $850-1000 \mathrm{~cm}^{-1}$, and $\delta(\theta)$ at the range from 500 to $720 \mathrm{~cm}^{-1}$.

The highest difference between control and transgenic fibres appeared at the two regions from 1200 to $1300 \mathrm{~cm}^{-1}$ and from 1025 to $1125 \mathrm{~cm}^{-1}$. The first corresponds to the in-plane stretching vibrations of pyranoid rings coupled with the in-plane bending of the $\mathrm{OH}$..... bonds and the last to the $v_{\text {as }}(\mathrm{C}-\mathrm{O}-\mathrm{C})$ vibrations.

The $\delta(\mathrm{OH} \cdots . . \mathrm{O})$ bands at about $1250 \mathrm{~cm}^{-1}$ exhibit reverse intensity to the $v(\mathrm{OH} \ldots \mathrm{O})$ vibration observed at $3400 \mathrm{~cm}^{-1}$ which suggests that the amount of the hydrogen bonds is different in the control and transgenic flax fibres and, therefore, a coupling between the elementary fibres from transgenic plant is weaker than in control. The substantial decrease in the intensity of the contour at about $1050 \mathrm{~cm}^{-1}$ for the transgenic fibre suggests that the cellulose polymers are shorter than for control because they contain less C-O-C bridges.

The data from IR study leads to the conclusion that cellulose polymer of transgenic fibres are shorter and more loosely bound than those from control plant. 
A
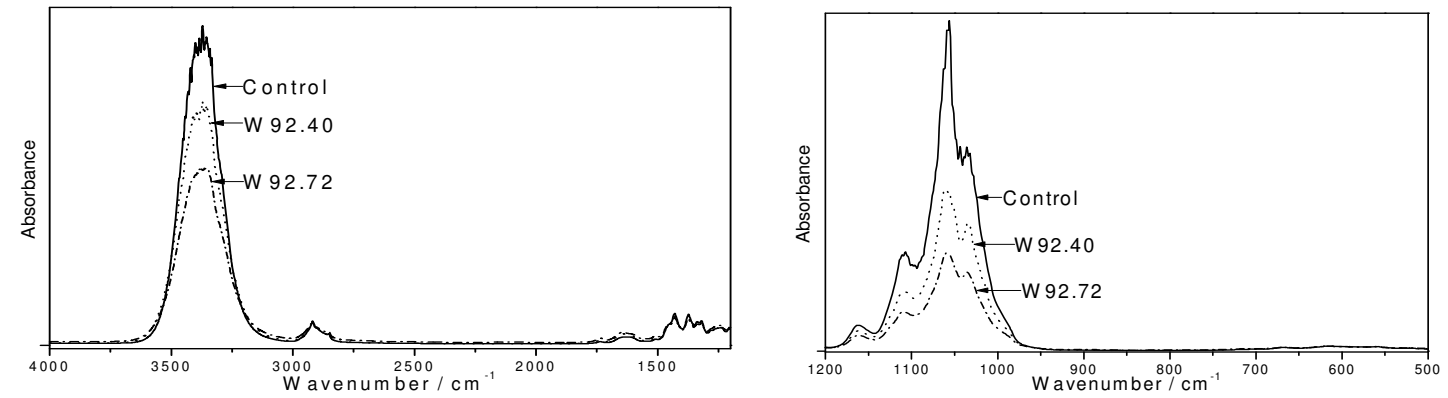

$3040-3680 \mathrm{~cm}^{-1}$

$1500-1800 \mathrm{~cm}^{-1}$

B
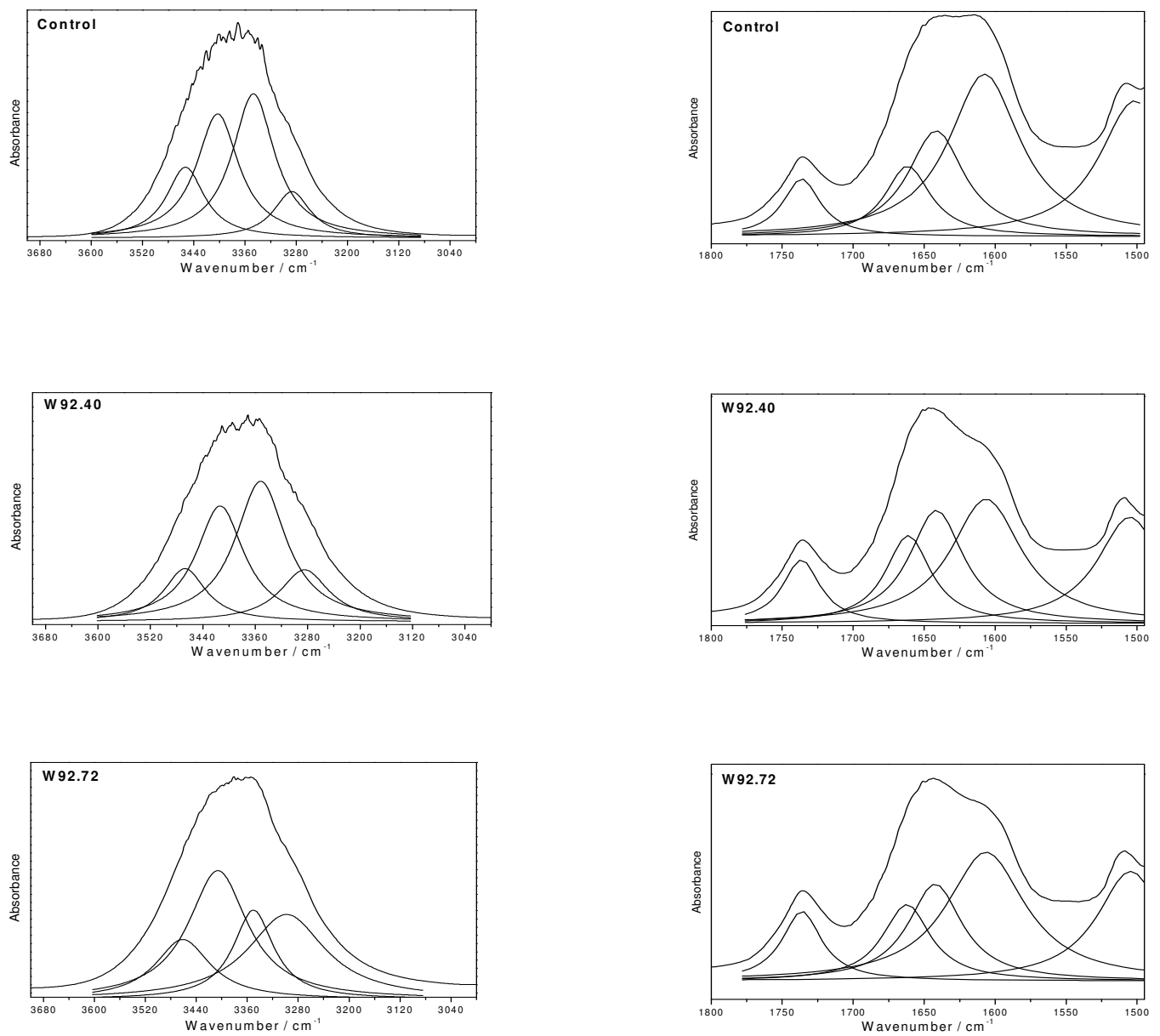

Figure 12 The IR analysis of fibres. (A) The IR spectra of the flax fibres obtained from the control and transgenic flax (W92.40, W92.72) (B) The deconvolution of the IR contours of control and transgenic (W92) flax fibres in the regions: 3040 - 3680 and $1500-1800 \mathrm{~cm}^{-1}$ into Lorenz components. The broad absorption band at $3400 \mathrm{~cm}^{-1}$ corresponds to the stretching $v(\mathrm{OH})$ mode of the free hydroxyl groups and those involved in the intra- and inter-molecular hydrogen bonds. The $1400-1800 \mathrm{~cm}^{-1}$ region of IR spectra characterize the pectin and lignin constituents of fibres. The component at about $1736 \mathrm{~cm}^{-1}$ corresponds to the $v_{\text {as }}(\mathrm{COO})$ vibrations of unconjugated carboxyl group of pectins. The position of band at $1662 \mathrm{~cm}^{-1}$ and 1608 and $1504 \mathrm{~cm}^{-1}$ are characteristic for lignins. 


\section{Discussion}

Flax (Linum usitatissimum L.) is an important source of natural fibres in several temperate regions of the world. Flax oil has long been used in human and animal diet and in industry as a source of oil and as the basal component or additive of various paints or polymers. Recently there has been a growing interest in the probiotic properties of flax and in its beneficial effects on coronary heart disease, some kinds of cancer and neurological and hormonal disorders [1-3]. The beneficial effects are mostly due to flax lipids. Flax oil is the richest plant source of linoleic and linolenic polyunsaturated fatty acids (PUFA), which are essential for humans since they cannot be synthesized in the organism and must be ingested with food. However, essential fatty acids are highly susceptible to oxidation and therefore flax oil has a very short shelf life.

The seedcake, the residual tissues after oil pressing, has scarcely been used only for animal feeding and some beneficial effect on animal growth was observed [47]. There is no report on seedcake biochemical composition and the effect of tissue components on accumulation and composition of fatty acids. Also there is no report on potential industrial application of biochemical components from seedcake.

Flax fibres derive from the phloem, and can be separated from the inner bark outside the cambium by the process called retting [34] For many years, flax fibres were mainly used for textile production. Now however, they are used as constituents of composite material for high-tech applications [48]. The strong, lightweight and low-cost flax fibres are used instead of conventional glass-fibres in reinforced plastic manufacture. Since they are biodegradable, their final composite product is easily recyclable. Very recently flax fibres application in biomedicine is also under investigation. Their beneficial role as wound dressing has been reported [7]

In order to improve oil stability and to expand seedcake and fibre application, mainly in medicine, transgenic flax plant has been generated and analyzed. It was expected that overexpression of three genes coding for key enzymes of flavonoid route will result in accumulation of broad spectrum of antioxidant molecules in each part of plant and thus making their basic products (oil, fibres) biotechnologically more valuable.

The initial step in the flavonoid route of the phenylpropanoid pathway is the synthesis of naringenin chalcone through condensation of three malonyl-CoA units with $p$-coumaroyl-CoA. The reaction is catalyzed by the action of chalcone synthase (CHS). The naringenin chalcone is a branch point for all flavonoid biosynthesis [49]. Chalcones are very labile compounds and could be accumulated as dihydrochalcones or rapidly converted
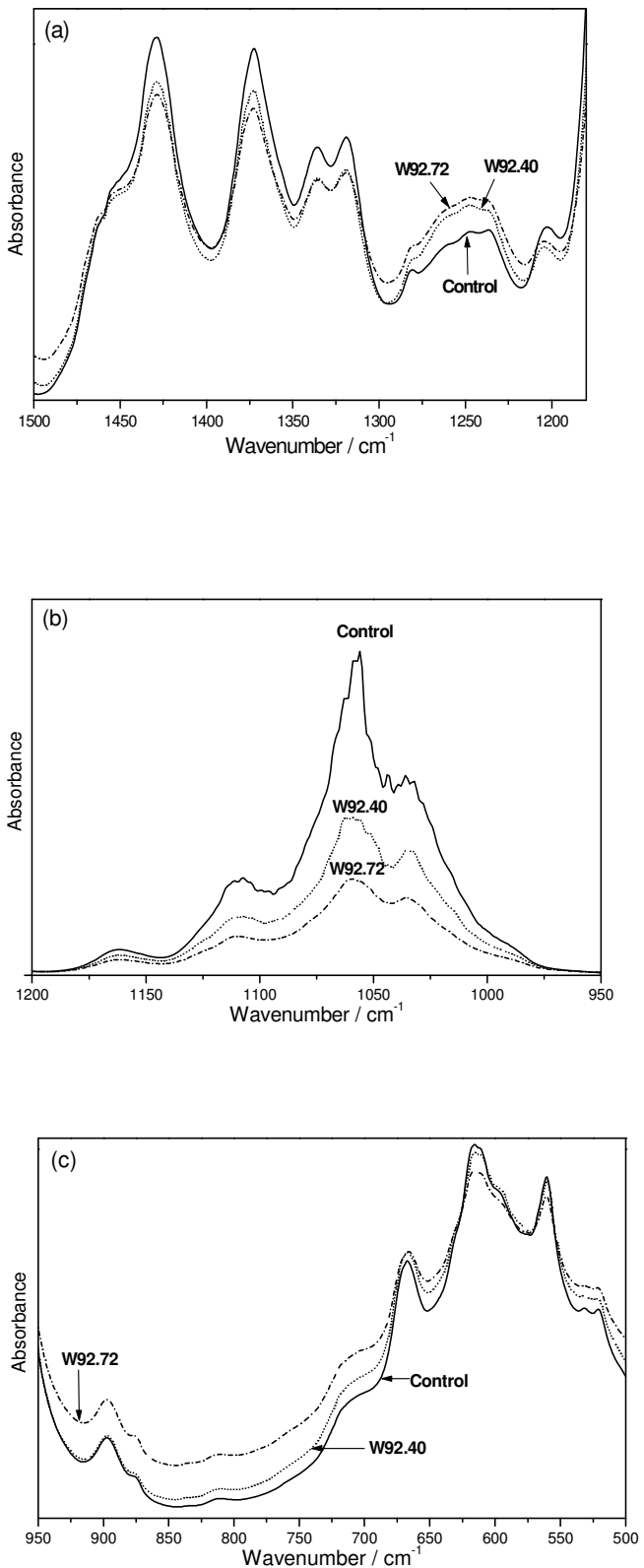

Figure 13 The deconvolution of the IR contours of fibres. The IR contours in the region (a) $1500-1200 \mathrm{~cm}^{-1}$, (b) $1200-950 \mathrm{~cm}^{-1}$ and (c) $950-500 \mathrm{~cm}^{-1}$ of the control and transgenic (W92.72, W92.40) flax fibres. All this regions are typical for flax cellulose consisting of some amounts of lignins and pectins.

to the colorless flavanone naringenin by the chalcone isomerase $(\mathrm{CHI})$. Flavanones act as a precursor for the synthesis of flavones and 3-OH-flavanones (dihydroflavonols). Dihydroflavonols can then be converted into flavonols by FLS (flavonol synthase) or into anthocyanins by DFR (dihydroflavonol 4-reductase).

Since our gene construction that has been introduced into transgenic flax contained cDNAs for $\mathrm{CHS}, \mathrm{CHI}$ and 
DFR enzyme, the flavonols and anthocyanins compound content was measured. The data obtained showed an increase in these compounds level in flaxseeds, seedcakes and fibres from plants of transgenic lines. It should be pointed out that measured flavonoid compounds in seed could be than found in seedcake extract and thus suggesting that the residual tissues after oil extraction from seeds appeared to be suitable source of biomedical valuable compounds. It is also important to notice that generated transgenic flax are stable in respect to expression of exogenously introduced genes since the field grown plants of third generation contained all transgenes and they are active which was confirmed by PCR analysis of transgenic plant with total mRNA as template.

Also interesting is the identification of increased quantity of phenolic acids and lignans in seedcake from transgenic seed. It is known that these compounds like flavonoids are the constituents of phenylpropanoid pathway however they are biosynthesized on different metabolic route. In view of the presented results there should be mechanism in operation coordinating their biosynthetic coregulation [50].

The core phenylpropanoid pathway converts phenylalanine to p-coumaric acid. Several branches radiate from this core reaction. Early branch point leads to the formation of simple phenylpropanoids like phenolic acids. The later incorporation of three malonyl-CoA molecules leads to generation of flavonoids. Lignans are dimers and lignins are the polymer of monolignol alcohol. Monolignol forms from coumaric acid, oxygen and methyl groups incorporated into the aromatic ring. This intermediate is then thought to be converted to respective aldehyde and then to the monolignol (coumaryl, ferulyl and sinapyl alcohols). The way in which lignans (dimer) and lignin (polymer) are formed from monolignol precursor is still poorly understood. Early suggestion was that the final stage of monolignol polymerization resulted from random coupling of monolignol units that did not require the involvement of enzymes. This opinion is now modified, it is evidenced that monolignol in the form of glycosides are transported to cell wall and then oxidized to form radicals that combine to produce polymer. There are several classes of enzymes present in cell wall that could catalyze monolignol oxidation including peroxidases, laccases, polyphenol oxidases and dirigent protein. Lignin polymer can be formed artificially by adding either peroxidase together with $\mathrm{H}_{2} \mathrm{O}_{2}$ or laccase with $\mathrm{O}_{2}$ which serve as oxidizing agent. This is the most substantial evidence that the same process might operating in vivo and suggests that monolignol dimers and polymers can be formed by random chemical interactions as well as by enzymatic control.
It is as yet unknown how these compounds (lignans) biosynthesis is regulated upon flavonoids overproduction [25]. We speculate that strong activation of flavonoids synthesis in transgenic flax and compounds accumulation might be the reason for this. The high concentrations of antioxidants may result in pro-oxidative activity. Thus the increase in antioxidative compound concentration upon CHS/CHI/DFR overexpression might result in local promoting of coumaric acid oxidation and monolignol radicals generation. This suggestion is supported by the finding that the level of coumaric acid in seedcake extract from control plant is about 30\% lower than this from transgenic plant.

Thus, the seedcake from transgenic seed appears as a richest source of SDG. It is important to notice the beneficial role of this compound for human health. There are several reports concluding the role of SDG in protection against different types of cancer $[49,51,52]$. SDG can be metabolized by the colonic microflora to the mammalian lignans, enterodiol and enterolactone. That is the reason why flax lignans exhibit weak estrogenic and antiestrogenic properties, in a tissue-specific manner, and have potential role in the prevention and treatment of breast cancer and other hormone dependent cancers $[53,54]$. A great number of animal model and human studies suggest that a higher intake of lignans reduces the risk of many chronic diseases including cardiovascular diseases and all types of diabetes [55-58]

Both flavonoids and phenolic acids were shown to exhibit antioxidant properties [11]. Since there was an increase in those compounds content detected in transgenic plants, an increase in antioxidant capacity was expected. Indeed the extract from transgenic seed and seedcake showed almost the same IC50 value and this was far lower than for control. Thus the accumulation of compounds from phenylpropanoid pathway mainly occurs in seedcake and strongly affects antioxidant potential of transgenic product.

It is known that flavonoids due to their hydrophilic nature only very partially coextract with the oil during its production. Even so the accumulation of antioxidants in seedcake was expected to affect fatty acid composition. Indeed oil produced from transgenic seeds contains more unsaturated fatty acids and the total level of fatty acids was also increased. Thus the higher quantity of phenylpropanoid compounds in seedcake indirectly affect the fatty acids stability perhaps by protection them against oxidation during technological process of oil production.

Flax retting is the process of fibre isolation and was faster in case of transgenic plant. In retting, bast fibre bundles are separated from the core, the epidermis and the cuticle [33]. This is accomplished by the cleavage of pectins and hemicellulose in the flax cell wall, a process 
mainly carried out by plant pathogens like filamentous fungi [34]. The retting efficiency depends on the degree of lignification. Since reduced lignin content in transgenic flax was observed the easier retting was expected. This was however not the case. Scanning electron microscopy does not show differences between transgenic and control fibres. Biochemical analysis of fibres suggests the increased level of catechine and acetylovanillone. Although the first resulted from flavonoid biosynthesis enhancement the second presumably derives from lignin degradation [56] The decrease in lignin content in fibres from transgenic plant agreed with this. Also decrease in the content of syringaldehyde in transgenic fibres which is the product of lignocellulose degradation [56] confirm that degradation process might occurs as more advanced in transgenic fibres than in control.

Infrared spectroscopy has been used for molecular characteristic of flax products for it was found to be very suitable for identification of the major chemical components and also found to provide information on the molecular changes in flax fibres caused by ageing, mechanical processing and chemical treatment $[34,41]$. Thus the main products of flax plant (oil, seedcake extract and fibres) were further analysed by this method and data compared to those from biochemical analysis.

The IR study of oil revealed that several compounds of hydrophilic nature coextract with the oil upon seed treatment with high pressure under low temperature. Among those compounds are flavonoids, phenolic acids and lignans. Although the method does not provide quantitative data on compounds content it is quite clear that their level is higher in oil from transgenic seed when compared to control. The detection of compounds of phenylpropanoid pathway in oil appears to be a good molecular background for protection of fatty acids from transgenic oil against oxidation which agrees with data from oil analyzed in TBARS method.

The observed changes in the intensity of bands characteristic for phenylpropanoids compounds in IR spectrum of seedcake extract from transgenic seed compared to control confirm the higher content of these compounds in extract from transgenic seedcake which was detected by UPLC analysis. Thus the conclusion is that the extract from transgenic seedcake contains the same phenylpropanoid compounds that were identified by UPLC analysis and they are in higher quantity when compared to control. Further the IR spectra helped to identify phenolic acids (ferulic vs. synapic) which were not resolved on UPLC column. Thus the IR spectra are suitable for detailed compounds analysis of seedcake extract.

The data from IR study confirmed the results of the biochemical analyses of the flax fibres and additionally suggests that arrangement of the cellulose polymer in the transgenic fibres differed from that in the control and a significant decrease in the number of hydrogen bonds was detected.

Thus the overall conclusion from the IR study of flax main product is that several compounds of phenylpropanoid pathway are accumulated in oil, seedcake and fibres upon three genes overexpression resulting in production of stable oil and fibres and seedcake extract ready for use in biomedicine.

\section{Conclusions}

The overall conclusion of this work is that the main product of flax (seeds, oil and fibres) from transgenic plant overexpressing three key genes from flavonoids route resulted in accumulation of several flavonoids, phenolic acids and lignans. All these compounds have an antioxidative nature and thus suggesting the use of modified fibres in production of fabrics for medicine (e.g. wound dressing), stable oil enriched in fatty acids for human diet and seedcakes for extraction of compounds with potential biomedical application. Their application in biomedicine is under investigation. Very recently those fabrics were successfully used in chronic wound therapy [7] To our best knowledge this is the first report describing the potential of all products from genetically engineered flax cultivated in semi-technical scale for wide biomedical application.

\section{Acknowledgements}

This study was supported by grant NR12 0009 06, NN302 101136, and NN310 079038, NN12017110 from the Polish Ministry of Science and Education

\section{Author details \\ ${ }^{1}$ Faculty of Biotechnology, University of Wrocław, Poland. ${ }^{2}$ Institute of Chemistry and Food Technology, Faculty of Economics and Engineering, University of Economics, Wrocław, Poland. ${ }^{3}$ Department of Food Science and Nutrition, Wroclaw Medical University, Nankiera 1, 50-140 Wrocław, Poland. ${ }^{4}$ Institute of Low Temperatures and Structure Research, Polish Academy of Sciences, Wrocław, Poland. ${ }^{5}$ Linum Fundation, Stablowicka 147/ 149,54-066 Wroclaw, Poland.}

\section{Authors' contributions}

MZ-carried out the biochemical analysis of seeds and seedcakes, drafted the manuscript. AK - carried out fibre biochemical analysis and participated in writing of the manuscript, LD- carried out IR analysis of seedcakes and oil, KS- carried out IR analysis of fibres, AP-participated in oil analysis, JHparticipates in interpretation of $I R$ analysis and conceived of IR part of study, JS- conceived of the study and participate in its design and coordination. All authors read and approved the final manuscript.

\section{Competing interests}

The authors declare that they have no competing interests.

Received: 2 July 2010 Accepted: 28 January 2011

Published: 28 January 2011

\section{References}

1. Huang S, Milles DE: Gamma-linolenic acid: Metabolism and its roles in nutrition and medicine. 1996. 
2. Huang S, Ziboh A: Gamma-linolenic acid: Recent advances in biotechnology and clinical applications.Edited by: Champaign IAP 2001.

3. Simopoulos AP: The importance of the ratio of omega-6/omega3 essential fatty acids. Biomedicine and Pharmacotheraphy 2002, 56:365-379.

4. Dribnenki J, Green AG: Linola 947- low linolenic flax. Canadian Journal of Plant Science 1995, 75:201-202.

5. Green AG: A mutant genotype of flax (Linum usitatissimum L.) containing very low levels of linolenic acid in its seed oil. Canadian Journal of Plant Science 1986, 66:499-503.

6. Czemplik M, Szopa J: Optimizing biomedical and industrial products development based on flax. CAB Reviews: Perspectives in Agriculture, Veterinary Science, Nutrition and Natural Resources 2009, 4(062).

7. Skórkowska-Telichowska K, Zuk M, Kulma A, Bugajska-Prusak A, Ratajczak K, Gąsiorowski K, Kostyn K, Szopa J: New dressing materials derived from transgenic flax products to treat long-standing venous ulcers-a pilot study. Wound Repair and Regeneration 2010, 18:168-179.

8. Holton TA, Cornish E: Genetic and biochemistry of anthocyanin biosynthesis. Plant Cell 1995, 7:1071-1083.

9. Martens S, Mithöfer A: Flavones and flavone synthases. Phytochemistry 2005, 66:2399-2407.

10. Winkel-Shirley B: Flavonoid Biosynthesis. A Colorful Model for Genetics, Biochemistry, Cell Biology, and Biotechnology. Plant Physiol 2001 126:485-493.

11. Pietta PG: Flavonoids as Antioxidants. J Nat Prod 2000, 63:1035-1042.

12. Harborne JB, Williams ChA: Advances in flavonoids research since 1992. Phytochemistry 2000, 55:481-504.

13. Cushni PT, Lamb A: Antimicrobial activity of flavonoids. Int J Antimicrob Agents 2005, 26:343-356.

14. Ryan KG, Swinny EE, Markham KR, Winefield C: Flavonoid gene expression and UV photoprotection in transgenic and mutant Petunia leaves. Phytochemistry 2002, 59:23-32.

15. Lee JH, Shim JS, Lee JS, Kim JK, Yang IS, Chung MS, Kim KH: Inhibition of pathogenic bacterial adhesion by acidic polysaccharide from green tea (Camellia sinensis). J Agric Food Chem 2006, 54:8717-8723.

16. Arora A, Muraleedharan GN, Strasburg GM: Structure activity relationships for antioxidant activities of a series of flavonoids in a liposomal system. Free Radical Biol Med 1998, 9:1355-1363.

17. Lorenc-Kukuła K, Amarowicz R, Oszmiański J, Doermann P, Starzyki M, Skała J, Żuk M, Kulma A, Szopa J: Pleiotropic Effect of Phenolic Compounds Content Increases in Transgenic Flax Plant. J Agric Food Chem 2005, 53:3685-3692.

18. Prescha A, Siger A, Lorenc-Kukuła K, Biernat J, Nogala-Kałucka M, Szopa J: Badania nad składem i podatnością na utlenianie oleju z nasion Inu modyfikowanego genetycznie. BROMAT.CHEM.TOKSYKOL 2008, XLI:286-292.

19. Lukaszewicz M, Matysiak-Kata I, Skała J, Fecka I, Cisowski W, Szopa J: Antioxidant capacity manipulation in transgenic potato tuber by changes in phenolic compounds content. Agric Food Chem 2004, 52:1526-1533.

20. Wróbel M, Zebrowski J, Szopa J: Polyhydroxybutyrate synthesis in transgenic flax. J.Biotech 2004, 107:41-54.

21. Logemann J, Schell J, Willmitzer L: A rapid method for the isolation of RNA from plant tissue. Anal Biochem 1987, 163:21-26.

22. Prescha A, Świędrych A, Biernat J, Szopa J: Increase in lipid content inpotato tubers modified by 14-3-3 gene overexpression. J Agric Food Chem 2001, 49:3638-3643.

23. Naczk M, Shahidi F: Extraction and analysis of phenolics in food. J Chromatogr A 2004, 1054:95-111.

24. Velasco L, Goffman D: Tocopherol,plastochromanol and fatty acid patterns in the genus Linum. Plant Syst Evol 2000, 221:77-88

25. Lorenc-Kukuła K, Zuk M, Kulma A, Czemplik M, Kostyn K, Skala J, Starzycki M, Szopa J: Enginiering flax with the GT Family I Solanum sogerandinum gycosyltransferase SsGT1 Confers Increased Resistance to Fusarium Infection. J Agric Food Chem 2009, 57(15):6698-6705.

26. Lukaszewicz M, Matysiak-Kata I, Aksamit A, Oszmianski J, Szopa J: 14-33 Protein regulation of the antioxidant capacity of transgenic potato tubers. Plant Sci 2002, 163:125-130.

27. Wróbel-Kwiatkowska M, Starzycki M, Żebrowski J, Oszmiański J, Szopa J: Engineering of PHB synthesis causes improved elastic properties of flax fibers. Biotechnol Prog 2007, 23:269-277.
28. Updegraff D: Semimicro determination of cellulose in biological materials. Anal Biochem 1969, 32:420-424.

29. liyama K, Wallis A: Determination of lignin in herbaceous plants by an improved acetyl bromide procedure. J Food Sci and Agri 1990, 51:145-161.

30. Melton LD, Smith G: Isolation of cell wall and fractionation of cell wall polysaccharides. 2001

31. Lorenc-Kukula K, Jafra S, Oszmianski J, Szopa J: Ectopic Expression of Anthocyanin 5-O-Glucosyltransferase in Potato Tuber Causes Increased Resistance to Bacteria. J Agric Food Chem 2005, 53:272-281.

32. Lukaszewicz M, Szopa J, Krasowska A: Susceptibility of lipids from different flax cultivars to peroxidation and its lowering by added antioxidants. Food Chem 2004, 88:225-231

33. Di Candilo M, Ranalli P, Bozzi C, Focher B, Mastromei G: Preliminary results of tests facing with the controlled retting of hemp. Industrial Crops and Products 2000, 11:197-203.

34. Easson LD, Molloy R: Retting-a key process in the production of high value fibre from flax. Outlook Agric 1996, 25:235-242.

35. Günzler H, Gremlich U: IR Spectroscopy. An Introduction, Wiley-VCh, Weinheim, Germany. 2002, Chapter 6.4:178.

36. Ram MS, Dowell FE, Seitz LM: FT-Raman spectra of unsoaked and $\mathrm{NaOH}$ soaked wheat kernels, bran, and ferulic acid. Cereall Chemistry 2003, 80:188.

37. Sebastian S, Sundaraganesan N, Manoharan S: Molecular structure, spectroscopic studies and first-order molecular hyperpolarizabilities of ferulic acid by density functional study. Spectrochimica Acta Part A: Molecular and Biomolecular Spectroscopy 2009, 74:312.

38. Socrates G: Infrared and Raman Characteristic Group Frequencies. J Wiley \& Sons, Ltd, Chichester, New York, Weinheim, Toronto, Brisbane, Singapore, third 2001:Chapter 2:50.

39. Wojtkowiak B, Chabanel M: Spectrochimie Moleculaire, Technique et Documentation. Warszawa: PWN; 1984:Chapter 4:114.

40. Zuk M, Dymińska L, Kulma A, Prescha A, Szopa J, Mączka M, Szołtysek K, Hanuza J: IR and Raman studies of oil and seedcake extracts from natural and genetically modified flax seeds. Spectrochemica Acta Part A 2010.

41. Edwards HGM, Farwell DW, Webster D: Raman microscopy of untreated natural plant fibres. Spectrochimica Acta Part A 1997, 53:2383-2392.

42. Jahn A, Schroder MW, Futing M, Schenzel K, Diepenbrock W: Characterization of alkali treated flax fibres by means of FT Raman spectroscopy and environmental scanning electron microscopy. Spectrochim Acta Part A 2002, 58:2271-2279.

43. Wróbel-Kwiatkowska M, Szopa J, Dymińska L, Mączka M, Hanuza J: Poly-3hydroxy butyric acid interaction with the transgenic flax fibers: FT-IR and Raman spectra of the composite extracted from a GM flax. Biotechnology Progress 2009, 25:1489-1498.

44. Boeriu CG, Bravo D, Gosselink RJA, van Dam JEG: Characerisation of structure-dependent functional properties of lignin with infrared spectroscopy. Industr Crops and Prod 2004, 20:205.

45. Wróbel-Kwiatkowska M, Żuk M, Szopa J, Dymińska L, Mączka M, Hanuza J: Poly-3-hydroxy butyric acid interaction with the transgenic flax fibers: FT-IR and Raman spectra of the composite extracted from a GM flax. Spectrochimica Acta Part A 2009, 73:286-294.

46. Htoo JK, Meng X, Patience JF, Dugan ME, Zijlstra RT: Effects of coextrusion of flaxseed and field pea on the digestibility of energy, ether extract, fatty acids, protein, and amino acids in grower-finisher pigs. J Anim Sci 2008, 86(11):2942-2951.

47. Bledzki AK, Faruk O, Sperber VE: Cars from Bio-Fibres. Macromol Mater Eng 2006, 291:449-457

48. Schijlen EG, Ric de Vos CH, van Tunen AJ, Bovy AG: Modification of flavonoid biosynthesis in crop plants. Phytochemistry 2004, 65:2631-2648

49. Adlercreutz H: Phytoestrogens and cancer. Lancet Oncol 2002, 3:364-373.

50. Besseau S, Hoffman L, Geoffroy P, Lapierre C, Pollet B, Legrand M: Flavonoid accumulation in Arabidopsis repressed in lignin synthesis affects auxin transport and plant growth. Plant Cell 2007, 19(1):148-162.

51. Donaldson MS: Nutrition and cancer: a review of the evidence for an anti-cancer diet. NutrJ 2004, 3(19).

52. Sung MK, Lautens M, Thompson LU: Mammalian lignans inhibit the growth of estrogen-independent human colon tumor cells. Anticancer res 1998, 18:1405-1408. 
53. Saffron A, Whitehead SR: Phytoestrogens oestrogen synthesis and breast cancer. Journal of Steroid Biochemistry \& Molecular Biology 2008, 108:186-195

54. Westcott ND, Muir AD: Flax seed lignan in disease prevention and health promotion. Phytochem ReV 2003, 2:401-417.

55. Arts ICV, Hollman PCH: Polyphenols and disease risk in epidemiologic studies. Am J Clin Nutr 2005, 81:S317-S325.

56. Loh PS, Miller A, Reeves AD, Harvey SM, Overnell J: Optimised recovery of lignin-derived phenols in a Scottish fjord by the CuO oxidation method. J Environ Monit 2008, 10(10):1187-1194.

57. Prasad K: Secoizolariciresinol diglucoside from flaxseed delays the development of type 2 diabetes in Zucker rat. Journal of Laboratory and Clinical Medicine 2001, 138(1):32-39.

58. Prasad K: Oxidative stress as a mechanism of diabetes in diabetic BB prone rats: Effect of secoisolariciresinol diglucoside (SDG). Molecullar and Cellular Biochemistry 2000, 209:89-96.

doi:10.1186/1472-6750-11-10

Cite this article as: Żuk et al:: Flavonoid engineering of flax potentiate its biotechnological application. BMC Biotechnology 2011 11:10.

\section{Submit your next manuscript to BioMed Central} and take full advantage of:

- Convenient online submission

- Thorough peer review

- No space constraints or color figure charges

- Immediate publication on acceptance

- Inclusion in PubMed, CAS, Scopus and Google Scholar

- Research which is freely available for redistribution

Submit your manuscript at www.biomedcentral.com/submit 